\title{
Perinatal maternal high-fat diet induces early obesity and sex-specific alterations of the endocannabinoid system in white and brown adipose tissue of weanling rat offspring
}

\author{
Mariana M. Almeida ${ }^{1} \dagger$, Camilla P. Dias-Rocha ${ }^{1} \dagger$, André S. Souza ${ }^{1}$, Mariana F. Muros ${ }^{1}$, \\ Leonardo S. Mendonca ${ }^{2}$, Carmen C. Pazos-Moura ${ }^{1}$ and Isis H. Trevenzoli ${ }^{1 *}$ \\ ${ }^{1}$ Instituto de Biofísica Carlos Chagas Filho, Universidade Federal do Rio de Janeiro, Rio de Janeiro, 21941-902, RJ, Brazil \\ ${ }^{2}$ Instituto de Saúde de Nova Friburgo, Universidade Federal Fluminense, Nova Friburgo, 28625-650, RJ, Brazil
}

(Submitted 9 May 2017 - Final revision received 25 August 2017 - Accepted 27 September 2017-First published online 7 November 2017)

\section{Abstract}

Perinatal maternal high-fat (HF) diet programmes offspring obesity. Obesity is associated with overactivation of the endocannabinoid system (ECS) in adult subjects, but the role of the ECS in the developmental origins of obesity is mostly unknown. The ECS consists of endocannabinoids, cannabinoid receptors (cannabinoid type-1 receptor (CB1) and cannabinoid type-2 receptor (CB2)) and metabolising enzymes. We hypothesised that perinatal maternal HF diet would alter the ECS in a sex-dependent manner in white and brown adipose tissue of rat offspring at weaning in parallel to obesity development. Female rats received standard diet (9\% energy content from fat) or HF diet (29\% energy content from fat) before mating, during pregnancy and lactation. At weaning, male and female offspring were killed for tissue harvest. Maternal HF diet induced early obesity, white adipocyte hypertrophy and increased lipid accumulation in brown adipose tissue associated with sex-specific changes of the ECS's components in weanling rats. In male pups, maternal HF diet decreased CB1 and CB2 protein in subcutaneous adipose tissue. In female pups, maternal HF diet increased visceral and decreased subcutaneous CB1. In brown adipose tissue, maternal HF diet increased CB1 regardless of pup sex. In addition, maternal HF diet differentially changed oestrogen receptor across the adipose depots in male and female pups. The ECS and oestrogen signalling play an important role in lipogenesis, adipogenesis and thermogenesis, and we observed early changes in their targets in adipose depots of the offspring. The present findings provide insights into the involvement of the ECS in the developmental origins of metabolic disease induced by inadequate maternal nutrition in early life.

\section{Key words: High-fat diet: Programming: Endocannabinoid system: White adipose tissue: Brown adipose tissue}

Obesity is a consequence of dysregulation between food intake and energy expenditure, mostly due to increased high-energetic or high-fat $(\mathrm{HF})$ diet consumption and sedentarism, resulting in excess of white adipose mass ${ }^{(1)}$. Obesity or overweight is present in two-thirds of women in the reproductive age in the USA, affecting not just their own health, but also their offspring ${ }^{(2)}$. Offspring are extremely sensitive to metabolic environmental stimuli or insults during gestation and lactation, which can result in altered physiology throughout life, a phenomenon known as 'metabolic programming'(3)

In adult obesity or obesity 'programmed' by early life insults, adipose tissue dysfunction seems to be an important contributor to the metabolic and hormonal alterations in humans and rodents. The body adipose mass is distributed in fat depots that present structural and functional differences, including white and brown adipose depots ${ }^{(4)}$. White adipose tissue (WAT) is organised in anatomical depots identified as visceral (VIS) and subcutaneous (SUB); VIS expansion is a greater predictor of mortality than SUB excess ${ }^{(5)}$. Compared with SUB, VIS is more vascular, innervated, sensitive to lipolysis, contains a larger number of inflammatory cells, has a greater percentage of large adipocytes, a greater capacity to generate free fatty acids and is more insulin-resistant, whereas SUB is more related to uptake of circulating free fatty acids and TAG levels ${ }^{(5)}$. An excess of these fat depots impairs endocrine function, as white adipocytes release several hormones and cytokines, such as leptin, adiponectin, TNF $\alpha$, monocyte chemoattractant protein-1 (MCP1) and plasminogen activator inhibitor 1 (PAI-1) ${ }^{(1,6)}$. Thus, overweight and obese subjects are at increased risk for several chronic diseases, including type 2 diabetes, hypertension and

Abbreviations: 2-AG, 2-arachidonoylglycerol; ACC, acetyl-CoA carboxylase; AEA, anandamide; AR $\beta 3$, adrenergic receptor $\beta 3$; BAT, brown adipose tissue; C, control group; CB1, cannabinoid type-1 receptor; $\mathrm{CB} 2$, cannabinoid type-2 receptor; $\mathrm{CEBP} \alpha$, CCAAT/enhancer binding protein $\alpha$; ECS, endocannabinoid system; ER, oestrogen receptor; FAAH, fatty acid amide hydrolase; HF, high fat; MAGL, monoacylglycerol lipase; PND, postnatal day; SUB, subcutaneous; T3, triiodothyronine; TH, tyrosine hydroxylase; UCP1, uncoupling protein-1; VIS, visceral; WAT, white adipose tissue.

$\dagger$ These authors contributed equally to this study.

*Corresponding author: I. H. Trevenzoli, email haraisis@biof.ufrj.br 
liver diseases ${ }^{(1)}$. On the other side, brown adipose tissue (BAT) is related to energy expenditure because of its thermogenic capacity. This thermogenic activity is completely dependent on catecholamine signalling via $\beta 3$ adrenergic receptors and is highly modulated by catabolic hormones such as thyroid hormone triiodothyronine (T3). In BAT, catecholamine or T3 signalling results in increased uncoupling protein-1 (UCP1) and heat production in brown adipocytes ${ }^{(7-9)}$.

Recently, a third adipocyte subset has been characterised, the 'brite' (brown-in-white) or 'beige' adipocytes, which presents molecular and functional characteristics of both white and brown adipocytes. Beige adipocytes are $\mathrm{UCP}^{+}$cells with a multilocular morphology mainly found within WAT SUB depots but are also found in the VIS depot ${ }^{(10)}$. The characterisation of the developmental origins of beige adipocytes is still in progress. Currently, two mechanisms have been considered for the formation of beige adipocytes: de novo beige adipogenesis and 'transdifferentiation' from unilocular white adipocytes ${ }^{(10,11)}$. Beige adipocyte accumulation in WAT depots is rapidly stimulated by cold exposure or $\mathrm{AR} \beta 3$ agonism, but it can also be triggered by several nutritional components ${ }^{(11)}$ and exercise-derived myokines ${ }^{(12)}$. This phenomenon is known as 'browning'(13).

WAT and BAT present all the components of the endocannabinoid system $(\mathrm{ECS})^{(14)}$, and it has been demonstrated that the ECS is usually overactive in obese subjects ${ }^{(15)}$. The ECS consists mainly of two receptors, the cannabinoid type-1 (CB1) and the cannabinoid type-2 (CB2), several endogenous ligands named endocannabinoids, anandamide (AEA) and 2-arachidonoylglycerol (2-AG) being the most active compounds, and ECS-metabolising enzymes, the fatty acid amide hydrolase (FAAH) and the monoacylglycerol lipase (MAGL). The endocannabinoids trigger several intracellular pathways following the stimulation of $\mathrm{CB} 1$ and $\mathrm{CB} 2$ receptors and their associated $G$ proteins, mainly inhibitory $G$ protein $^{(16,17)}$. In WAT, the endocannabinoids stimulate lipogenesis and adipogenesis, whereas in BAT they decrease thermogenesis $^{(17)}$. These effects contribute to obesity development, and the ECS is currently considered as a therapeutic target for metabolic diseases ${ }^{(18)}$

Despite the effects of the ECS in the adipocyte physiology and ECS deregulation in adult obesity, a few studies have been conducted to investigate the role of the ECS in the developmental origins of obesity, and they are mainly focused on the central regulation of metabolism at adulthood ${ }^{(19-23)}$. However, the differential effects of maternal HF diet on the ECS's components in VIS WAT, SUB WAT and BAT of the offspring during early life are unknown.

Using a rat model of metabolic programming, we previously demonstrated that perinatal maternal consumption of a moderate HF diet increased pre-gestational body fat in rat dams, increased milk content of total proteins, TAG and cholesterol at weaning, and induced early obesity development in male offspring $^{(24)}$, suggesting overnutrition of the HF pups during lactation. Endocannabinoids are arachidonic acid-derived active lipids ( $n-6$ fatty acid family), and the ECS's components can be modulated by dietary fat composition, with the ECS's overactivation triggered by HF 'western diets' and the ECS's attenuation observed in response to $n-3$ fatty acid-enriched diets ${ }^{(25,26)}$. Therefore, we hypothesised that the lipid overload during lactation would alter the ECS's profile in adipose tissue depots of the HF offspring at weaning.

We have also demonstrated that perinatal maternal HF diet induces early obesity in male offspring in parallel to hyperleptinaemia and central leptin resistance ${ }^{(24)}$. A tight crosstalk has been reported between the ECS and leptin. Central leptin infusion inhibits WAT lipogenesis and local endocannabinoids production in rats ${ }^{(27)}$. Moreover, leptin action is inversely associated with activation of the ECS, and leptin resistance in obese models can lead to overactivation of the $\operatorname{ECS}^{(28,29)}$. Therefore, we hypothesised that early obesity and leptin resistance could also modulate the ECS's components in adipose tissue of the HF offspring. Because the presence of sex steroid hormone response elements in the promoter of the cannabinoid receptors and the ECS-metabolising enzymes, and an in vivo regulation of the ECS by oestrogen ${ }^{(30-34)}$, we further hypothesised that perinatal maternal HF diet would alter the protein abundance of the ECS's components in adipose tissue of rat offspring in a sex-specific manner, in parallel to adipose tissue morphological and molecular signature changes and early obesity development.

\section{Methods}

\section{Ethics statement}

All procedures with animals were approved by the Animal Care and Use Committee of the Carlos Chagas Filho Biophysics Institute (process no. 123/14). The handling of the experimental animals followed the principles adopted in the UK and Brazil according to Brazilian Law no. 11.794/2008 ${ }^{(35,36)}$.

\section{Animals}

In all, thirty female Wistar rats (Rattus norvegicus Berkenhout, 1769), $60 \mathrm{~d}$ old and weighing 180-220 g, were obtained from the Center of Reproduction Biology of the Federal University of Rio de Janeiro, Rio de Janeiro, Brazil. They were kept in a controlled temperature environment $\left(23 \pm 2^{\circ} \mathrm{C}\right)$ with a photoperiod of $12 \mathrm{~h}$ (07.00-19.00 hours - light and 07.00-19.00 hours - dark). Water and the experimental diets were offered on an ad libitum basis to the animals throughout the study.

\section{Dietary treatments and experimental design}

Nulliparous 60-d-old female rats were randomly assigned to two dietary treatments ( $n$ 15/group): control group (C), which received a standard diet for rodents ( $9 \%$ of the energy content from fat), and a HF group, which received a HF diet (28.6\% of the energy content from fat). In the HF diet, lard was used as fat source, and we also added $1 \%$ soya oil to provide the minimal amount of $n$ - 3 fatty acid for adequate development of the rats. Both diets were pelleted and contained approximately $16.3 \mathrm{~kJ} / \mathrm{g}$ of energy and followed the AIN-93 recommendations for micronutrients ${ }^{(24,37)}$. Diet composition is described in Table 1. Female rats were fed these diets during 8 weeks before mating and throughout gestation and lactation. After mating in a 
Table 1. Maternal diet macronutrient composition

\begin{tabular}{lcrr}
\hline Macronutrients & Amount $(\mathrm{g})$ & $\mathrm{kJ} / \mathrm{g}$ & $\% \mathrm{~kJ}$ \\
\hline Control diet & & & \\
$\quad$ Protein & 220 & 3.68 & 22.6 \\
$\quad$ Lipids & 40 & 1.50 & 9.4 \\
Carbohydrates & 660 & 11.03 & 68 \\
$\quad$ Total & 1000 & 16.22 & 100 \\
High-fat diet & 169.6 & & \\
Protein & 214.9 & 2.84 & 17.3 \\
Lipids & 530.3 & 4.70 & 28.6 \\
Carbohydrates & 1092 & 8.86 & 54.1 \\
$\quad$ Total & & 16.34 & 100 \\
\hline
\end{tabular}

3:1 ratio (female:male), pregnant rats were housed in individual standard rat cages.

At birth, the litters were adjusted to three males and three females per each dam, a number that maximises lactation performance $^{(38)}$. During lactation, offspring body weight and naso-anal length were monitored, and, at weaning (postnatal day 21), male and female pups were euthanised. All pups were killed between 09.00 and 12.00 hours in a fed state. Blood samples were taken by cardiac puncture under anaesthesia ( $55 \mathrm{mg}$ per $/ \mathrm{kg}$ BW ketamine and $100 \mathrm{mg} / \mathrm{kg}$ BW xylazine) followed by decapitation. Plasma samples were stored at $-80^{\circ} \mathrm{C}$. Retroperitoneal (VIS) and inguinal (SUB) WAT and BAT were dissected, weighted, snap frozen in liquid $\mathrm{N}_{2}$ and stored at $-80^{\circ} \mathrm{C}$ for determination of protein content. VIS WAT, SUB WAT and BAT samples were also collected for histology analysis. For each experimental procedure, rats from at least six different litters per group were used to avoid litter effects.

\section{Plasma metabolites}

Blood samples were collected in heparinised tubes and centrifuged (1233 $\boldsymbol{g}$ for $15 \mathrm{~min}, 4^{\circ} \mathrm{C}$ ) for plasma separation. Plasma adiponectin levels were determined using a specific rat Adiponectin ELISA Kit from Merck Millipore, with an assay sensitivity of $0.155 \mathrm{ng} / \mathrm{ml}$. Plasma leptin, insulin, PAI-1, IL $\beta$, TNF $\alpha$ and MCP1 were measured by specific rat Milliplex Adipokine Panel Metabolism Assay from Merck Millipore. Intraassay CV was $<10 \%$ for all analytes. Plasma oestradiol levels were determined using a RIA kit (MP Diagnostics) with intraassay variation of $15.7 \%$. Plasma levels of total T3 and free T4 were measured by RIA, with intra-assay CV of 4.7 and $2.8 \%$, respectively.

\section{Western blotting analysis}

We used the Western blotting assay to detect the protein content of CB1, CB2, FAAH, MAGL, oestrogen receptor $\alpha(\mathrm{ER} \alpha)$ and $\mathrm{ER} \beta$ in VIS WAT, SUB WAT and BAT samples. We also detected the protein content of perilipin, PPAR $\gamma$, CCAAT/enhancer binding protein $\alpha(\mathrm{CEBP} \alpha)$, acetyl-CoA carboxylase (ACC), fatty acid synthase (FAS), UCP1 and tyrosine hydroxylase (TH) in VIS WAT and SUB WAT. As regards BAT, we detected UCP1, AR 33 and TH. The protein content of glyceraldehyde-3-phosphate dehydrogenase, $\beta$-actin or cyclophilin was used as loading control. The WAT samples were homogenised in $\mathrm{pH} 7 \cdot 4$ lysis buffer (20 mm TRIS-HCl, $10 \mathrm{~mm} \mathrm{NaF,} 1 \%$ NP40, $150 \mathrm{~mm} \mathrm{NaCl}$, $5 \mathrm{mM}$ EDTA, 0,1\% SDS) containing complete protease inhibitor cocktail (Roche Diagnostics). The BAT samples were homogenised in $\mathrm{pH} 8.0$ lysis buffer $(50 \mathrm{~mm}$ TRIS-HCl, $150 \mathrm{~mm} \mathrm{NaCl}$, $0.5 \%$ deoxy glycolic acid, $1 \%$ NP40, 0.1\% SDS). After centrifugation, the total protein content of the supernatant was quantified using a Pierce ${ }^{\mathrm{TM}}$ BCA Protein Assay Kit (Thermo Scientific). The samples were denatured in sample buffer (50 mм TRIS-HCl, pH 6·8, 1 \% SDS, 5\% 2-mercaptoethanol, $10 \%$ glycerol, $0.001 \%$ bromophenol blue) and heated at $95^{\circ} \mathrm{C}$ for $5 \mathrm{~min}$. Total proteins were analysed by SDS-PAGE, with a $10 \%$ polyacrylamide gel, and transferred onto polyvinylidene difluoride membranes (Hybond-P 0.45 $\mu \mathrm{m}$ PVDF; Amersham Biosciences). The membranes were incubated with Tween TBS buffer (T-TBS) containing 5\% non-fat dry milk for $90 \mathrm{~min}$ to block non-specific binding sites. Thereafter, the membranes were incubated overnight at $4^{\circ} \mathrm{C}$ with specific primary antibodies. The membranes were washed and incubated with peroxidase labelled-specific secondary antibodies for $2 \mathrm{~h}$ at room temperature. All blots were washed and incubated with a luminogen detection reagent (Amersham ECL Prime Western Blotting Detection Reagent; Amersam Bioscience). Information about primary and secondary antibodies is described in Table 2. Chemiluminescent signal was detected by ImageQuant LAS 4000 equipment followed by densitometric analyses (GE Healthcare Life Sciences). For each protein analysed by Western blotting, we used six or seven samples per group, and each sample was obtained from a different rat from a different litter.

\section{Histology}

Fragments of WAT and BAT were fixed in $4 \% \mathrm{w} / \mathrm{v}$ formaldehyde phosphate buffer $(0 \cdot 1 \mathrm{~m}, \mathrm{pH} 7 \cdot 2)$ for $48 \mathrm{~h}$ at room temperature. The fragments were processed and embedded in Paraffin, sectioned at $5 \mu \mathrm{m}$ and stained with haematoxylineosin for light microscopy observation. After processing and histological staining, the slides were observed under the optical microscope (Olympus BX51 microscope; Olympus Optical Brazil). Digital images were acquired (LC Evolution camera, TIFF format, 36-bit colour, $1280 \times 1024$ pixels) and analysed using Image Pro plus 6.0 software (Media Cybernetics). In WAT samples, the diameter of the adipocytes was analysed. For this analysis, six non-consecutive fields were used for each animal, in a total of six to eight animals from a different litter per experimental group. In BAT samples, the lipid content in the histological sections of BAT was analysed by image segmentation, and the data were expressed as percentage of the field area occupied by lipid vesicles.

\section{Statistical analysis}

The sample size was calculated by using the G*Power 3.1.9.2 $\operatorname{program}^{(39)}$ and on the basis of the effect of maternal consumption of a HF diet on plasma and molecular parameters of the offspring at postnatal day 21 from previous study ${ }^{(24)}$. As regards plasma parameters, a sample size of eight animals per group would provide the appropriate power $(1-\beta=0 \cdot 8)$ to 
Table 2. Primary and secondary antibodies used for Western blot

\begin{tabular}{|c|c|c|c|c|c|}
\hline \multirow[b]{2}{*}{ Proteins } & \multicolumn{2}{|l|}{ Primary antibody } & \multicolumn{3}{|c|}{ Secondary antibody } \\
\hline & Company & Dilution & Company & Dilution & Specificity \\
\hline CB1 & Cayman & $1: 500$ & Amersham Bioscience, Inc. & $1: 5000$ & Anti-rabbit \\
\hline CB2 & Sigma-Aldrich & $1: 1000$ & Cell Signaling Technology & $1: 10000$ & Anti-mouse \\
\hline FAAH & Cayman & $1: 200$ & Amersham Bioscience, Inc. & $1: 5000$ & Anti-rabbit \\
\hline MAGL & Santa Cruz Biotechnology & $1: 1000$ & Amersham Bioscience, Inc. & $1: 10000$ & Anti-rabbit \\
\hline $\mathrm{ER} a$ & Merck Millipore & $1: 1000$ & Sigma-Aldrich & $1: 10000$ & Anti-mouse \\
\hline $\mathrm{ER} \beta$ & Cell Signaling Technology & $1: 1000$ & Amersham Bioscience, Inc. & $1: 10000$ & Anti-rabbit \\
\hline Perilipin & Cell Signaling Technology & $1: 1000$ & Amersham Bioscience, Inc & $1: 10000$ & Anti-rabbit \\
\hline PPAR $y$ & Cell Signaling Technology & $1: 1000$ & Amersham Bioscience, Inc. & $1: 10000$ & Anti-rabbit \\
\hline CEBPa & Cell Signaling Technology & $1: 1000$ & Amersham Bioscience, Inc. & $1: 10000$ & Anti-rabbit \\
\hline $\mathrm{ACC}$ & Cell Signaling Technology & $1: 1000$ & Amersham Bioscience, Inc. & $1: 10000$ & Anti-rabbit \\
\hline FAS & Cell Signaling Technology & $1: 1000$ & Amersham Bioscience, Inc. & $1: 10000$ & Anti-rabbit \\
\hline UCP1 & Abcam & $1: 1000$ & Amersham Bioscience, Inc & $1: 10000$ & Anti-rabbit \\
\hline $\mathrm{AR} \beta 3$ & Santa Cruz Biotechnology & $1: 1000$ & Invitrogen & $1: 10000$ & Anti-goat \\
\hline $\mathrm{TH}$ & Merck Millipore & $1: 1000$ & Amersham Bioscience, Inc. & $1: 10000$ & Anti-rabbit \\
\hline GAPDH & Cell Signaling & $1: 10000$ & Amersham Bioscience, Inc. & $1: 10000$ & Anti-rabbit \\
\hline Cyclophilin & Applied Biosystems ${ }^{\mathrm{TM}}$, Thermo Fisher Scientific & $1: 5000$ & Amersham Bioscience, Inc. & $1: 5000$ & Anti-rabbit \\
\hline$\beta$-Actin & Sigma-Aldrich & $1: 10000$ & Amersham Bioscience, Inc. & $1: 10000$ & Anti-mouse \\
\hline
\end{tabular}

CB1, cannabinoid type-1 receptor; CB2, cannabinoid type-2 receptor; FAAH, fatty acid amide hydrolase; MAGL, monoacylglycerol lipase; ERa, oestrogen receptor a, ER $\beta$, oestrogen receptor $\beta, \mathrm{CEBP} \alpha$, CCAAT/enhancer binding protein $\alpha$; ACC, acetyl-CoA carboxylase; FAS, fatty acid synthase; UCP1, uncoupling protein 1; AR $\beta 3$, adrenergic receptor $\beta 3$; $\mathrm{TH}$, tyrosine hydroxylase; GAPDH, glyceraldehyde-3-phosphate dehydrogenase.

identify significant differences $(\alpha=0.05)$ in the variables analysed, with an effect size $d=1 \cdot 33$, two-tailed test, and a sample size ratio $=1$. For molecular parameters, a sample size of six animals per group would provide the appropriate power $(1-\beta=0.8)$ to identify significant differences $(\alpha=0.05)$ in the variables analysed, with an effect size $d=1 \cdot 81$, two-tailed test, and a sample size ratio $=1$.

The statistical comparisons were performed using the software GraphPad Prism (GraphPad Software Inc.). For all analyses, normality was assessed by the Kolmogorov-Smirnov test, and Grubb's test was used to detect outliers.

Body weight and length during lactation were analysed using three-way ANOVA test with maternal diet, offspring sex and postnatal day (PND) as factors, and multiple comparisons were assessed by Tukey's post hoc test, considering $P<0.05$ as statistically significant. Adipose tissue mass, plasma parameters, white adipocyte diameter and lipid accumulation in BAT at weaning were analysed by two-way ANOVA with maternal diet and offspring sex as factors, and multiple comparisons were assessed by Tukey's post hoc test, considering $P<0.05$ as statistically significant. As regards molecular data, statistical tests were used for comparisons between control and HF offspring of the same sex. For measures that were normally distributed, a parametric test was used (Student's unpaired $t$ test), and, for those measures that were not normally distributed, we used non-parametric statistics (Mann-Whitney $U$ test). Results are shown as mean values with their standard errors, considering $P<0.05$ as statistically significant.

\section{Results}

Body weight of the offspring during lactation was significantly affected by postnatal day (PND) of pups $(P<0 \cdot 0001)$, maternal diet $(P<0.0001)$ and $\operatorname{sex}(P<0.0001)$. There was also an interaction between PND and maternal diet $(P<0.0001)$.
Multiple comparisons indicated that maternal HF diet increased body weight of male and female offspring from the 12th PND until weaning compared with sex-matched C pups (12th PND: male $+16.6 \%, \quad P<0.0001 ;$ female $+15.2 \%, \quad P<0.001$; 15th PND: male $+19.7 \%, P<0.0001 ;$ female $+16.9 \%, P<0.0001$; 18th PND: male $+20.0 \%, P<0.0001$; female $+21.2 \%, P<0.0001$; 21th PND: male $+13.7 \%, P<0.0001$; female $+17.5 \%, P<0.0001$ ) (Fig. 1(a)).

Body length of offspring was significantly affected by PND of pups $(P<0.0001)$, maternal diet $(P<0.0001)$ and sex $(P<0.0001)$. There was also an interaction between PND and maternal diet $(P<0 \cdot 0001)$. Maternal HF diet increased male and female offspring length at the 18th PND compared with sexmatched C pups (male $+4.7 \%, P<0.01$; female $+4.3 \%$, $P<0.01$ ), but this difference remained only in female pups at weaning $(+4.1 \%, P<0.01)$ (Fig. 1(b)).

At weaning, maternal HF diet affected the retroperitoneal (VIS WAT), inguinal (SUB WAT) and BAT mass of the offspring $(P<0.0001)$, and an interaction between maternal diet and sex was only observed in VIS WAT $(P<0 \cdot 05)$. Multiple comparisons indicated that maternal HF diet increased the mass of VIS WAT (male: +5.52-fold, $P<0.0001$; female +3.87-fold, $P<0.0001$ ), SUB WAT (male +3-fold, $P<0 \cdot 001$; female $+3 \cdot 20$-fold, $P<0.0001$ ), and BAT (male $+29.4 \%, P<0.0001$; female $+27.6 \%$, $P<0.0001$ ) compared with sex-matched C pups (Fig. 1(c)).

Maternal HF diet affected leptin and adiponectin plasma levels of the offspring at weaning $(P<0 \cdot 0001)$, being leptinemia was also affected by sex $(P<0 \cdot 05)$. Maternal HF diet increased leptinemia in male and female offspring (male $+53.2 \%, P<0.05$; female $+84.2 \%, P<0.0001$ ) as well as adiponectinemia (male $+84.6 \%, P<0.0001$; female $+61.1 \%, P<0 \cdot 0001)$ compared with sex-matched $C$ pups (Table 3 ). Both maternal diet and sex affected plasma levels of insulin $(P<0.01$ and $P<0.05$, respectively). Multiple comparisons indicated that maternal $\mathrm{HF}$ diet increased insulin levels only in female offspring $(+65.9 \%$, 


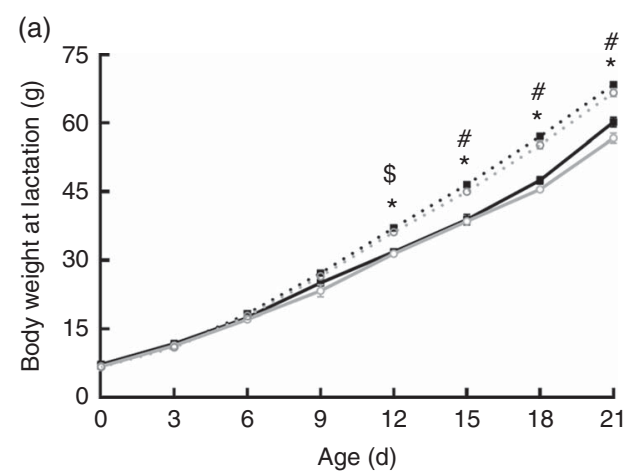

Age effect $(P<0.0001)$, maternal diet effect $(P<0.0001)$ sex effect $(P<0.0001)$

Interaction: maternal diet $\mathrm{x}$ age $(P<0.0001)$ (b)

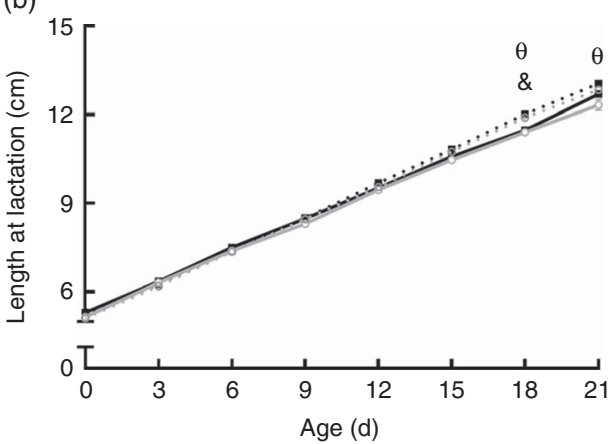

Age effect $(P<0.0001)$, maternal diet effect $(P<0.0001)$, sex effect $(P<0.0001)$

Interaction: maternal diet $\mathrm{x}$ age $(P<0.0001)$ (c)

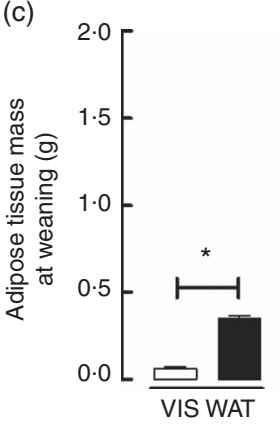

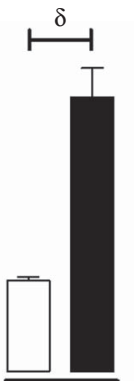

$\overline{\text { SUB WAT }}$
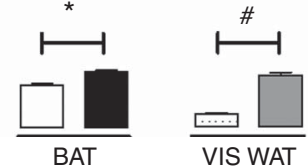
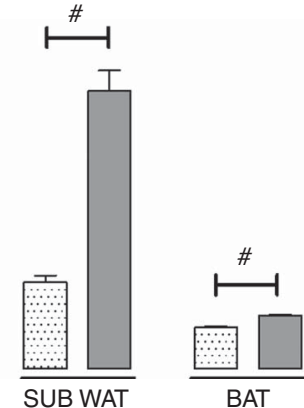

Maternal diet effect $(P<0.0001)$, interaction $(P<0.05)$ in VIS WAT

Fig. 1. Effect of maternal high-fat (HF) diet on body weight and naso-anal length during lactation and adiposity of rat offspring at weaning. (a) Body weight of control (C) and HF male and female offspring during lactation, (b) naso-anal length of $\mathrm{C}$ and $\mathrm{HF}$ male and female offspring during lactation, (c) mass of visceral white adipose tissue (VIS WAT), subcutaneous WAT (SUB WAT) and brown adipose tissue (BAT) of $C$ and HF male and female offspring at weaning. Values are means ( $n 10$ pups

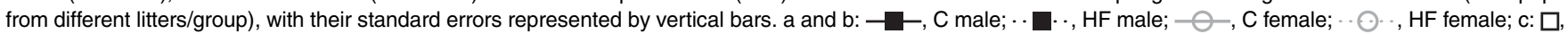
C male; $\square, \mathrm{HF}$ male; $\square, \mathrm{C}$ female; $\square$, HF female. Statistically significant differences were determined by three-way ANOVA (factors: postnatal day, maternal diet and sex) to analyse the body weight and length data, and by two-way ANOVA (factors: maternal diet and sex) to analyse the adipose tissue mass data. Tukey's post hoc test: ${ }^{*} P<0.0001, \delta P<0.001, \& P<0.01$ for $\mathrm{C}$ male $v$. HF male offspring; $\# P<0.0001, \$ P<0.001, \theta P<0.01 \mathrm{C}$ for female $v$. HF female offspring.

Table 3. Effect of maternal high-fat (HF) diet on plasma metabolites of male and female offspring at weaning

(Mean values with their standard errors)

\begin{tabular}{|c|c|c|c|c|c|c|c|c|c|c|c|}
\hline \multirow[b]{3}{*}{ Parameters } & \multicolumn{8}{|c|}{ Offspring groups } & & & \\
\hline & \multicolumn{2}{|c|}{ C male } & \multicolumn{2}{|c|}{ HF male } & \multicolumn{2}{|c|}{ C female } & \multicolumn{2}{|c|}{ HF female } & \multicolumn{3}{|c|}{ Source of variation } \\
\hline & Mean & SEM & Mean & SEM & Mean & SEM & Mean & SEM & Maternal diet & Sex & Interaction \\
\hline Adiponectin $(\mu \mathrm{g} / \mathrm{ml})$ & 8.71 & 0.76 & $16 \cdot 08^{\star}$ & 0.67 & $10 \cdot 81$ & 0.73 & $17.42 \dagger$ & 1.09 & $<0.0001$ & $<0.05$ & NS \\
\hline Leptin (ng/ml) & 4.38 & 0.61 & $6 \cdot 71^{*}$ & 0.62 & $4 \cdot 12$ & 0.31 & $7.59 \dagger$ & 0.49 & $<0.0001$ & NS & NS \\
\hline Insulin (ng/ml) & 1.02 & 0.05 & $1 \cdot 18$ & 0.16 & 1.29 & 0.27 & $2.14 \dagger$ & 0.22 & $<0.05$ & $<0.01$ & NS \\
\hline Oestradiol (pg/ml) & 147.50 & $6 \cdot 87$ & $136 \cdot 20$ & 5.38 & $143 \cdot 30$ & $12 \cdot 80$ & $130 \cdot 60$ & $8 \cdot 13$ & NS & NS & NS \\
\hline T3 (ng/ml) & 1.64 & 0.04 & 1.66 & 0.05 & 1.39 & 0.04 & 1.50 & 0.03 & NS & $<0.0001$ & NS \\
\hline T4 (ng/ml) & 51.61 & 3.0 & $56 \cdot 31$ & $3 \cdot 1$ & 55.51 & 3.8 & 51.40 & 2.8 & NS & NS & NS \\
\hline PAl-1 (pg/ml) & 94.09 & $6 \cdot 79$ & $122 \cdot 10$ & 10.50 & $85 \cdot 55$ & $7 \cdot 21$ & 93.47 & 9.79 & NS & $<0.05$ & NS \\
\hline $\mathrm{IL}-1 \beta(\mathrm{pg} / \mathrm{ml})$ & $47 \cdot 21$ & 7.58 & 38.40 & 4.49 & 29.83 & 2.96 & $30 \cdot 22$ & 3.73 & NS & $<0.05$ & NS \\
\hline TNFa $(\mathrm{pg} / \mathrm{ml})$ & 0.96 & 0.18 & 0.93 & 0.17 & 0.86 & 0.12 & 0.82 & 0.21 & NS & NS & NS \\
\hline MCP1 (ng/ml) & $133 \cdot 70$ & 19.80 & 171.40 & 23.40 & $158 \cdot 20$ & $23 \cdot 10$ & $210 \cdot 50$ & 41.80 & NS & NS & NS \\
\hline
\end{tabular}

C, control; T3, triiodothyronine; T4, thyroxine; PAI-1, plasminogen activator inhibitor 1; MCP1, monocyte chemoattractant protein-1.

* Statistical difference between $C$ male and HF male groups $(P<0.05$; two-way ANOVA followed by Tukey's post hoc test).

† Statistical difference between $C$ female and HF female groups $(P<0.05$; two-way ANOVA followed by Tukey's post hoc test).

$P<0 \cdot 05)$ compared with sex-matched C pups (Table 3). Offspring sex also affected plasma levels of T3 $(P<0 \cdot 0001)$, PAI-1 $(P<0.05)$ and IL-1 $\beta(P<0.05)$. However, multiple comparisons did not show maternal HF diet effect. We did not find maternal diet or sex effects on plasma levels of oestradiol, T4, TNF- $\alpha$ and MCP1 (Table 3). 
In the present study, we characterised the effect of maternal HF diet on the protein content of the ECS's components in different adipose tissue compartments. In VIS WAT, maternal HF diet did not change the CB1 content in male pups, whereas it increased CB1 in female pups $(+52 \cdot 4 \%, P<0.05)$ (Fig. 2(a)). In contrast, maternal HF diet did not affect $\mathrm{CB} 2$ content in male or female pups (Fig 2(b)). Concerning the metabolising enzymes, maternal HF diet increased FAAH content in male pups $(92.2 \%, P<0.05)$, without changes in female pups (Fig. 2(c)), whereas it did not change MAGL content in male or female pups (Fig. 2(d)).

In SUB WAT, maternal HF diet decreased CB1 content in both male $(-48.9 \%, P<0.05)$ and female $(-49.6 \%, P<0.05)$ pups (Fig. 2(a)), whereas it decreased CB2 content only in male pups $(-58 \cdot 14 \%, P<0.05)$ (Fig. $2(\mathrm{~b})$ ). In addition, maternal HF diet increased FAAH content in both male $(+3 \cdot 8$-fold, $P<0.05)$ and female $(+2 \cdot 2$-fold, $P<0.05)$ pups (Fig. $2(\mathrm{c}))$, whereas it increased MAGL content only in female pups $(+47.6 \%$, $P<0.05$ ) (Fig. 2(d)).

In BAT, maternal HF diet increased CB1 content in both male $(+63.8 \%, P<0.05)$ and female $(+70.5 \%, P<0.05)$ pups (Fig. $2($ a) $)$, whereas it decreased CB2 content only in female pups $(-52.0 \%$, $P<0.05$ ) (Fig. 2(b)). In addition, maternal $\mathrm{HF}$ diet increased FAAH content only in female pups $(+81.4 \%, P<0.05)$ (Fig. $2(\mathrm{c}))$, whereas it increased MAGL content in both male $(+70.2 \%$, $P<0.05)$ and female $(+1 \cdot 3$-fold, $P<0 \cdot 05)$ pups (Fig. $2(\mathrm{~d})$ ).

As regards VIS WAT morphology, the adipocyte diameter was significantly affected by maternal diet $(P<0.0001)$ and sex $(P<0 \cdot 01)$. Multiple comparisons indicated that maternal HF diet increased adipocyte diameter in both male $(+39.2 \%, P<0.05)$ and female $(+35.3 \%, P<0.05)$ offspring compared with sexmatched C pups (Fig. 3(a) and (b)). Maternal HF diet did not change perilipin content in VIS WAT of male or female pups (Fig. 3(c)). In contrast, maternal HF diet decreased PPAR $\gamma$ content in VIS WAT only in female pups $(-17.7 \%, P<0.05)$ (Fig. 3(d)), and it decreased CEBP $\alpha$ content only in male pups $(-30.9 \%, P<0.05)$ (Fig. 3(e)). Maternal HF diet increased ACC content in VIS WAT of male pups $(+25.8 \%, P<0.05)$ and decreased ACC content in VIS WAT of female pups $(-66 \%$, $P<0.05$ ) (Fig. 3(f)). Maternal HF diet did not change FAS content in male or female offspring (Fig 3(g)).

As regards SUB WAT morphology, the adipocyte diameter was significantly affected by maternal diet $(P<0.0001)$, and there was an interaction between maternal diet and sex $(P<0.0001)$. Multiple comparisons indicated that maternal HF diet increased adipocyte diameter in both male $(+61.7 \%, P<0.05)$ and female $(+37.8 \%, P<0.05)$ offspring (Fig. 3(a) and (b)). Maternal HF diet did not change perilipin content in SUB WAT of male pups (Fig. 3 (c)), but it increased the perilipin content in female pups $(+2 \cdot 8-$ fold, $P<0.05$ ) (Fig. 3(c)). Maternal HF diet did not change PPAR $\gamma$ and CEBP $\alpha$ content in male or female offspring (Fig. 3(d) and (e)), but it increased ACC content only in female pups $(+63.5 \%$, $P<0.05$ ) (Fig. 3(f)). Maternal HF diet did not change FAS content in male or female offspring (Fig. 3(g))

In BAT, maternal diet affected tissue lipid accumulation $(P<0 \cdot 0001)$. Multiple comparisons indicated that maternal $\mathrm{HF}$ diet increased lipid accumulation in BAT of both male $(+14.1 \%$; $P<0.05)$ and female $(+28.8 \% ; P<0.05)$ offspring (Fig. 4(a) and (b)) compared with sex-matched $\mathrm{C}$ pups. Maternal HF diet did not change AR $\beta 3$ content in BAT of male or female pups (Fig. 4(c)).

To access the effect of maternal HF diet on markers of catecholamine tissue levels and thermogenesis in VIS WAT, SUB WAT and BAT of the offspring, we measured the tissue content of TH and UCP1 (Fig. 5). Maternal HF diet decreased TH content in VIS WAT of male pups $(-32 \%, P<0.05)$ and SUB WAT of female pups $(-35 \%, P<0.05)$, whereas it increased TH in BAT of female pups (+3-fold, $P<0 \cdot 05$ ) (Fig. 5(a)). Maternal HF diet decreased UCP1 content in SUB WAT of male pups $(-56 \%, P<0.05)$, and it increased UCP1 content in BAT of female pups (+3.4-fold, $P<0 \cdot 05$ ) (Fig. 5(b)).

As regards $\mathrm{ER} \alpha$ and $\mathrm{ER} \beta$ content in WAT and BAT, maternal HF diet decreased $\operatorname{ER} \alpha(-47.8 \%, P<0.05)$ and $\operatorname{ER} \beta(-46.8 \%$, $P<0.05$ ) in VIS WAT of female pups (Fig. 6(a) and (b)). In SUB WAT, maternal HF diet increased $\mathrm{ER} \alpha$ in male pups $(+77.4 \%$, $P<0.05)$ and decreased $\mathrm{ER} \alpha(-39.1 \%, P<0.05)$ in female pups, whereas it did not change ER $\beta$ in both sexes (Fig. 6(a) and (b)). In BAT, maternal HF diet increased $\mathrm{ER} \alpha$ only in male offspring $(+77.0 \%, P<0.05)$, whereas it increased $\operatorname{ER} \beta$ only in female pups (+89.4\%, $P<0.05$ ) (Fig. 6(a) and (b)).

The effect of maternal HF diet on the molecular profile in VIS WAT, SUB WAT and BAT of male and female offspring is presented in an integrated view in Table 4.

\section{Discussion}

In the present study, we used an experimental model of obesity induced by maternal HF diet consumption during pregestational period, gestation and lactation. First, we confirmed and expanded the characterisation of the obese phenotype already observed in male offspring at weaning ${ }^{(24,40)}$. In addition, we also characterised the phenotype of female offspring, as we hypothesised that there would be a differential molecular ECS profile in adipose tissue associated with early obesity in male and female HF offspring.

Maternal HF diet increased body weight, body length and adiposity in both male and female offspring at weaning. According to our previous study, early obesity in HF offspring is likely a consequence of overnutrition during lactation, as breast milk of the HF progenitors presents a higher concentration of lipids, protein and carbohydrates ${ }^{(24)}$. Increased adiposity is commonly associated with reduced plasma levels of adiponectin and increased levels of leptin ${ }^{(41,42)}$. However, in neonates, the association between body mass and adiponectinemia seems to be a direct relationship, whereas children and adults exhibit an inverse association ${ }^{(43)}$. Here, we showed that maternal HF diet increased plasma levels of adiponectin in male and female offspring at weaning. In agreement with our results, the adiponectinemia of human neonates is positively related to body weight and length during the three weeks after birth ${ }^{(44)}$, and it presents a positive association with increased SUB $\operatorname{adiposity}^{(43)}$. In contrast, the hyperleptinaemia and increased adiposity observed in male pups confirmed our previous results ${ }^{(24)}$ and corroborates results from other studies ${ }^{(45-47)}$. We have previously shown that this phenotype of HF male offspring persists during adolescence and adulthood ${ }^{(24,40,48)}$. 
(a)

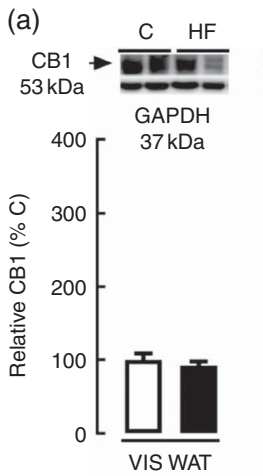

(b)
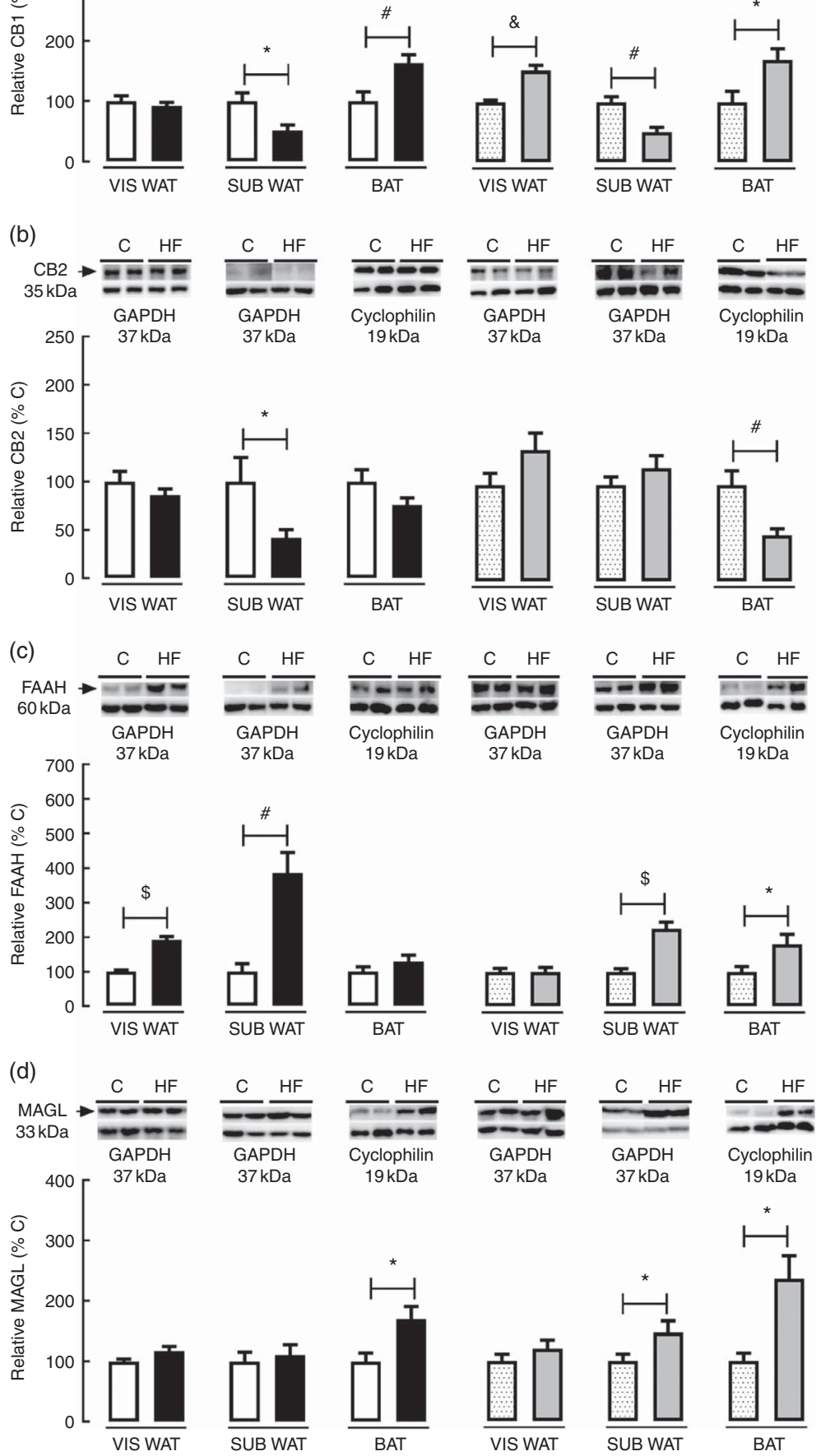

Fig. 2. Effect of maternal high-fat (HF) diet on the endocannabinoid system (ECS) components in white and brown adipose tissue of rat offspring at weaning. (a) Protein content of type-1 cannabinoid receptor (CB1) in visceral white adipose tissue (VIS WAT), subcutaneous WAT (SUB WAT) and brown adipose tissue (BAT) of control (C) and HF male and female offspring, (b) protein content of type-2 cannabinoid receptor (CB2) of $\mathrm{C}$ and HF male and female offspring, (c) protein content of fatty acid amide hydrolase (FAAH) of $\mathrm{C}$ and $\mathrm{HF}$ male and female offspring, and (d) protein content of monoacylglycerol lipase (MAGL) of $\mathrm{C}$ and HF male and female offspring. Values are means ( $n$ 6-7 pups from different litters/group), with their standard errors represented by vertical bars. $\square, C$ male; $\square, \mathrm{HF}$ male; $\square, \mathrm{C}$ female; $\square, \mathrm{HF}$ female; GAPDH, glyceraldehyde-3-phosphate dehydrogenase. Statistically significant differences were determined by student's unpaired $t$ test between $C$ and HF offspring per each sex. ${ }^{*} P<0.05, \# P<0.01, \& P<0.001, \$ P<0.0001$. 
(a)

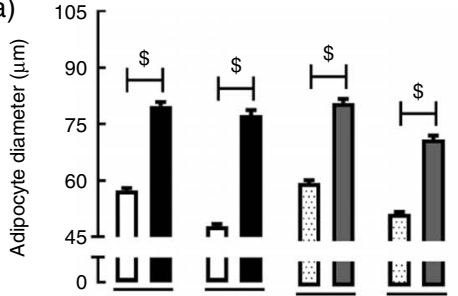

VIS WAT SUB WAT VIS WAT SUB WAT Maternal diet effect $(P<0.0001)$, sex effect $(P<0.01)$ in VIS WAT, interaction $(P<0.0001)$ in SUB WAT

(c)

C $\mathrm{HF} \quad \mathrm{C} \quad \mathrm{HF} \quad \mathrm{C} \quad \mathrm{HF} \quad \mathrm{C} \quad \mathrm{HF}$
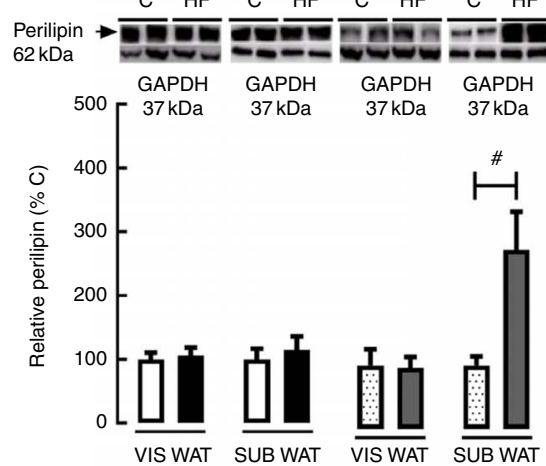

(d)

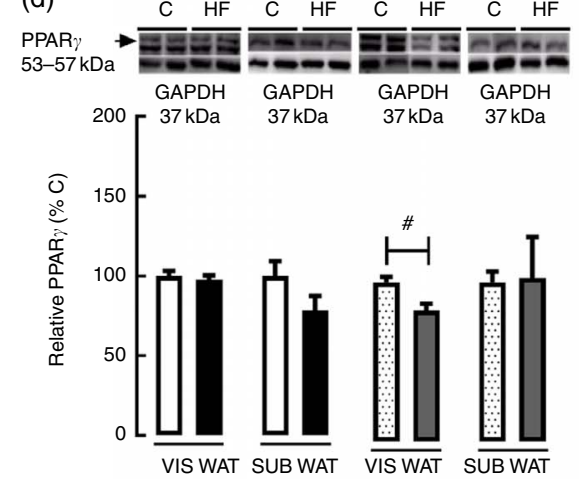

(f)

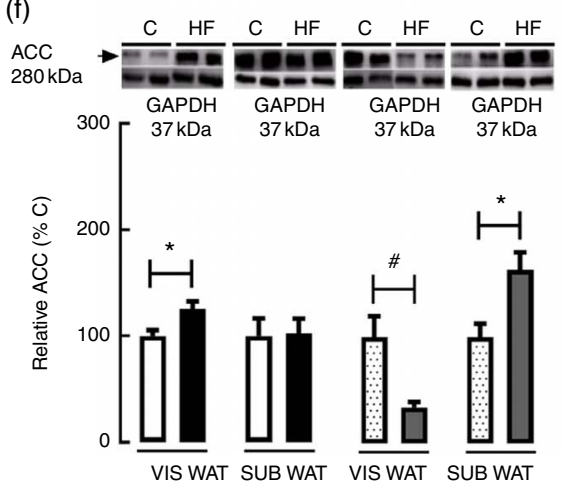

(b)

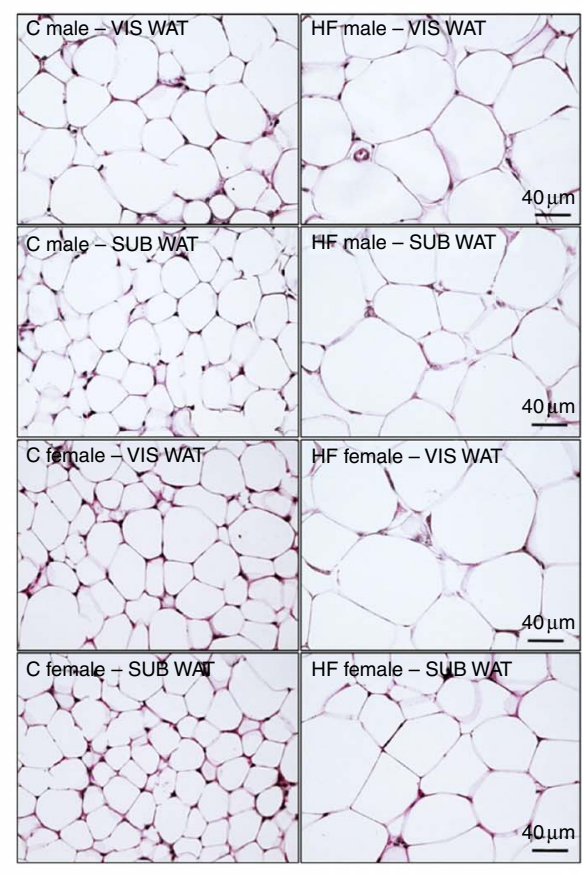

(e)

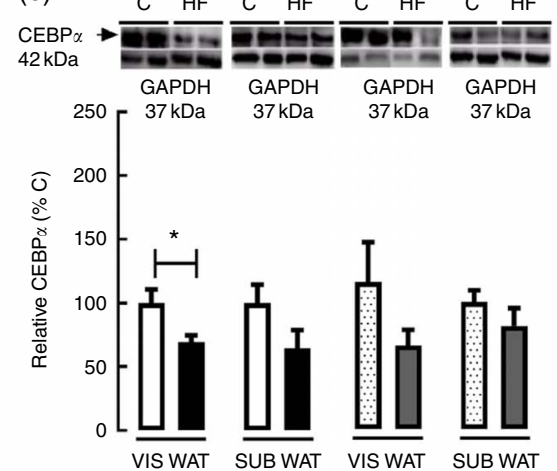

(g)

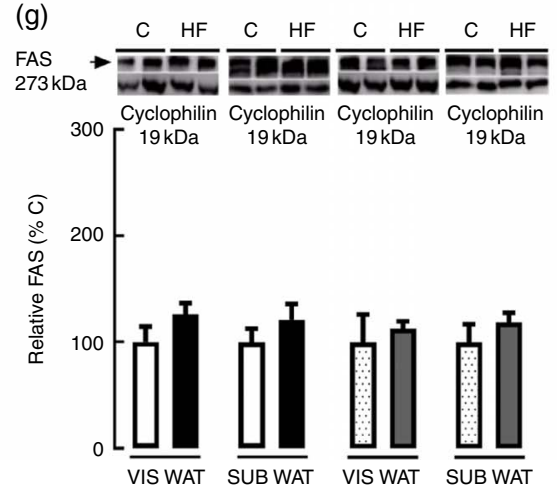

Fig. 3. Effect of maternal high-fat (HF) diet on adipocyte morphology and adipogenic and lipogenic markers in white adipose tissue of rat offspring at weaning. (a) Adipocyte diameter in the visceral white adipose tissue (VIS WAT) and subcutaneous WAT (SUB WAT) of control (C) and HF male and female offspring, (b) photomicrography of $\mathrm{C}$ and HF male and female offspring, (c) protein content of perilipin in $\mathrm{C}$ and HF male and female offspring, (d) protein content of PPARy of $\mathrm{C}$ and $\mathrm{HF}$ male and female offspring, (e) protein content of CCAAT/enhancer binding protein a (CEBPa) of $\mathrm{C}$ and HF male and female offspring, ( $\mathrm{f}$ ) protein content of acetyl-CoA carboxylase $(A C C)$ of $\mathrm{C}$ and HF male and female offspring, and (g) protein content of fatty acid synthase (FAS) of $\mathrm{C}$ and $\mathrm{HF}$ male and female offspring. Values are means ( $n 6$ or 8 pups from different litters/group), with their standard errors represented by vertical bars. $\square$, C male; $\square$, HF male; … C female; $\square$, HF female. Statistically significant differences were determined by two-way ANOVA (factors: maternal diet and sex) to the adipocyte diameter data. Tukey's post hoc test: $\$ P<0.0001$. Student's unpaired $t$ test between $\mathrm{C}$ and HF offspring per each sex was used to analyse the lipogenic and adipogenic markers' data. ${ }^{*} P<0.05$. \# $P<0.01$. 
(a)

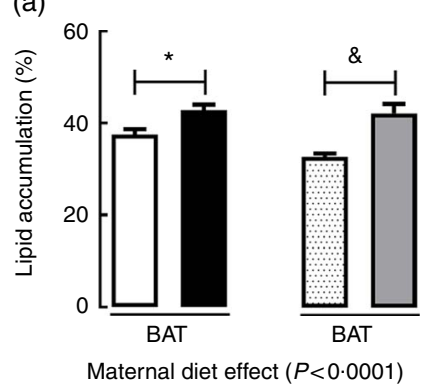

(c)

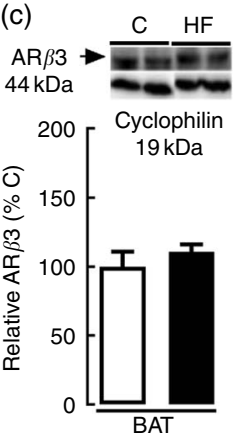

(b)

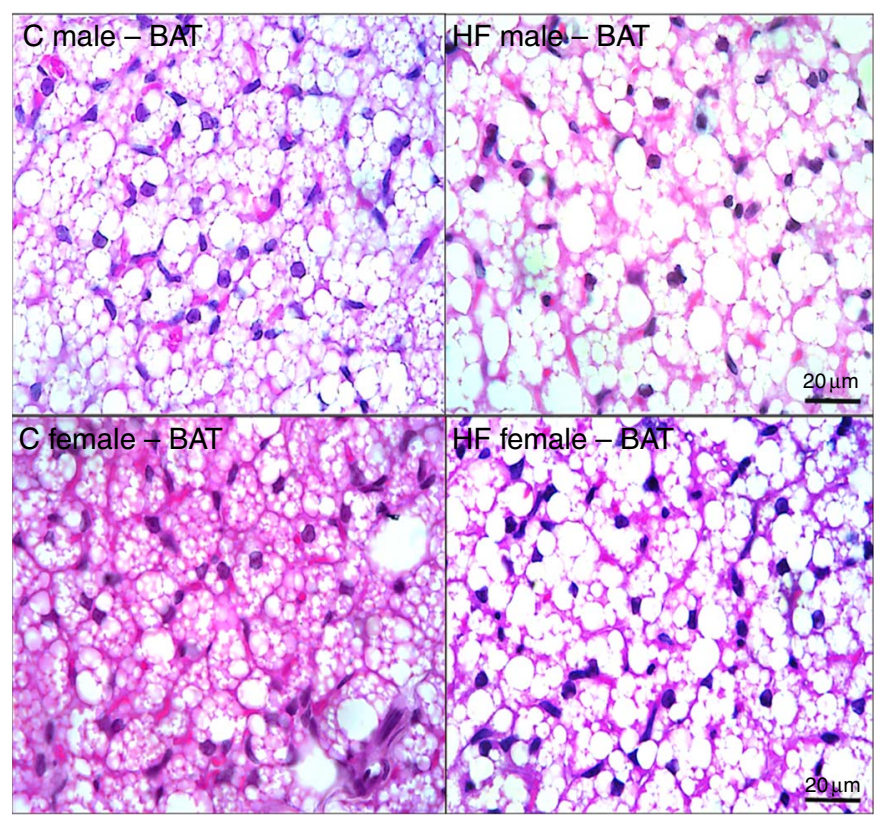

Fig. 4. Effect of maternal high-fat (HF) diet on adipocyte morphology and protein content of $\beta 3$ adrenergic receptor (AR $\beta 3$ ) in brown adipose tissue of rat offspring at weaning. (a) Lipid accumulation in brown adipose tissue (BAT) of control (C) and HF male and female offspring, (b) photomicrography of $\mathrm{C}$ and HF male and female offspring, (c) protein content of $\mathrm{AR} \beta 3$ of $\mathrm{C}$ and $\mathrm{HF}$ male and female offspring. Values are means ( $n 6$ or 8 pups from different litters/group), with their standard errors represented by vertical bars. $\square$, C male;, HF male;.., $\mathrm{C}$ female; $\square$, HF female. Statistically significant differences were determined by two-way ANOVA (factors: maternal diet and sex) to analyse lipid accumulation data. Tukey's post hoc test: ${ }^{*} P<0.05, \& P<0.001$. Student's unpaired $t$ test between $\mathrm{C}$ and HF offspring per each sex was used to analyse $\operatorname{AR} \beta 3$ content data.

At weaning, hyperleptinaemia was associated with decreased hypothalamic leptin-signalling markers, suggesting central leptin resistance ${ }^{(24)}$. This is important because leptin resistance is associated with positive energy balance and contributes to obesity development by increasing food intake and decreasing energy expenditure ${ }^{(49)}$.

Obesity and leptin resistance have been associated with tissuespecific alterations of the ECS's signalling in the central nervous system and peripheral tissues of adult rodents and humans ${ }^{(50-55)}$. In the present study, we demonstrated that maternal HF diet resulted in differential regulation of the ECS's components across WAT and BAT depots in male and female offspring at weaning, a period of life considered as a critical window for developmental origins of health and disease $(\mathrm{DOHaD})^{(56)}$

Adequate levels of endocannabinoids in early life likely have a key role in feeding and body weight regulation, as it was demonstrated that AEA and 2-AG are present in placenta and breast milk of healthy subjects ${ }^{(57-59)}$. In addition, AEA treatment during lactation programmes energy metabolism in a short-term and long-term manner ${ }^{(60,61)}$. The local levels of endocannabinoids are regulated by the action of important metabolising enzymes, such as FAAH and MAGL. Maternal HF diet increased FAAH content in VIS WAT of male offspring at weaning, suggesting decreased local content of $\mathrm{AEA}^{(62,63)}$, which is preferentially metabolised by this enzyme ${ }^{(62,63)}$. Increased FAAH content in male VIS WAT may be related to the obesity phenotype, as an increase of FAAH content in the adipose tissue of obese men ${ }^{(64)}$ and a positive correlation between FAAH activity in adipocytes and $\mathrm{BMI}^{(65)}$ has been demonstrated.
In white adipocytes, endocannabinoids activate de novo lipogenesis $^{(66)}$. Maternal HF diet increased the content of the lipogenic enzyme ACC in VIS WAT of male offspring and decreased the adipogenic factor $\operatorname{CEBP} \alpha^{(67)}$. This profile may contribute to hypertrophy of the preexisting adipocytes, as the differentiation of new pre-adipocytes to store extra lipids generated by increased lipogenesis might be impaired, based on the reduced content of $\operatorname{CEBP} \alpha$. In accordance, we observed increased adipocyte diameter in VIS WAT of HF male offspring. Hypertrophic adipocytes present a high metabolic turnover, with increased lipogenesis, reduced capacity of free fatty acids uptake and increased fatty acid release, resulting in increased lipid flux into non-adipose organs, raising the risk to develop insulin resistance and cardiovascular diseases throughout life ${ }^{(68)}$.

As regards, CB1 regulation in VIS WAT of female offspring, maternal HF diet increased CB1 content, which can also contribute to increased lipogenesis, adipocyte hypertrophy and higher adipose tissue mass ${ }^{(66)}$, as we observed in this group. Previous study showed that maternal exposure to a highly energetic and palatable diet increases CB1 mRNA levels in visceral adipose tissue of female adult rat offspring ${ }^{(21)}$. Here, we demonstrated that maternal HF diet also increased the protein levels of CB1, and this alteration occurs already in early life. Increased expression of CB1 in WAT is associated with hyperinsulinaemia, which is restored by CB1 antagonist administration $^{(69)}$. In the present study, we observed increased CB1 and hyperinsulinaemia only in female HF offspring, which may contribute to insulin resistance ${ }^{(70,71)}$ 
(a)

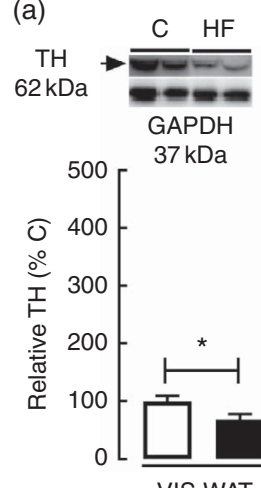

(b)

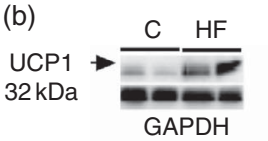

$37 \mathrm{kDa}$

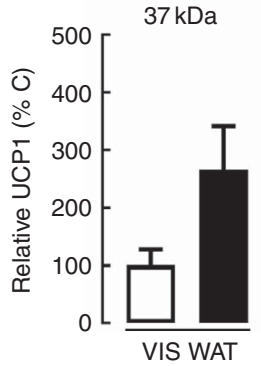

C $\mathrm{HF}$

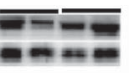

Cyclophilin

$19 \mathrm{kDa}$

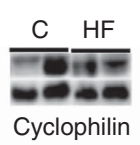

Cyclophilin $19 \mathrm{kDa}$

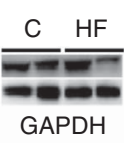

$37 \mathrm{kDa}$
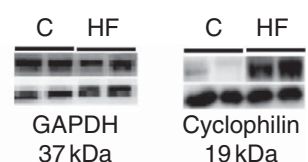

$37 \mathrm{kDa}$
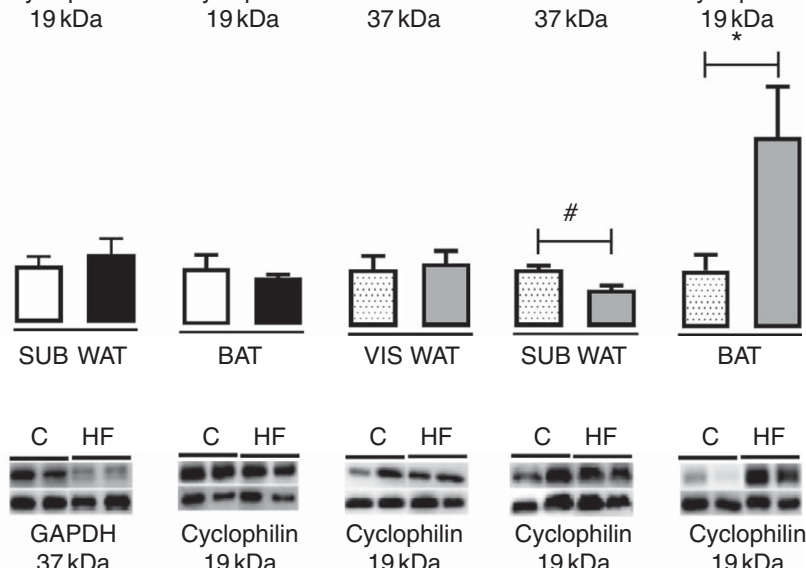

$19 \mathrm{kDa}$

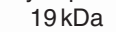

$37 \mathrm{kDa}$
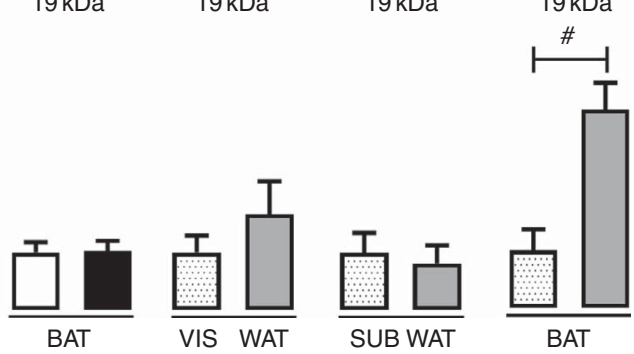

Fig. 5. Effect of maternal high-fat (HF) diet on thermogenic markers in white and brown adipose tissue of rat offspring at weaning. (a) Protein content of tyrosine hydroxylase (TH) in visceral white adipose tissue (VIS WAT), subcutaneous WAT (SUB WAT) and brown adipose tissue (BAT), (b) protein content of uncoupling protein-1 (UCP1) of control (C) and HF male and female offspring. Values are means ( $n 6$ or 8 pups from different litters/group), with their standard errors represented by vertical bars. $\square, \mathrm{C}$ male; $\square, \mathrm{HF}$ male; $\square, \mathrm{C}$ female; $\square$, HF female; GAPDH, glyceraldehyde-3-phosphate dehydrogenase. Statistically significant differences were determined by Student's unpaired $t$ test between $C$ and HF offspring per each sex. ${ }^{*} P<0.05, \# P<0.01$.

CB1 expression in adipocytes is down-regulated by $\operatorname{PPAR}^{(72)}$, and maternal HF diet decreased PPAR $\gamma$ content in the VIS WAT of female offspring. Therefore, the decreased PPAR $\gamma$ content may contribute to increased CB1 content observed in this depot. PPARy is an important factor for both lipogenesis and adipogenesis in $\mathrm{WAT}^{(67)}$, and it increases the number of small adipocytes and decreases large adipocytes in WAT of obese rats ${ }^{(73)}$. PPAR $\gamma$ knockout mice fed with a HF diet accumulate a similar amount of excess fat compared with wild-type mice, but this extra lipid storage is associated with more hypertrophied adipocytes ${ }^{(74,75)}$. In contrast, a contrary profile is observed with PPARy agonist treatment, such as thiazolidinedione (TZD), which increases the adipocyte number and decreases the adipocyte area in WAT depots under control or HF diet in rats ${ }^{(7)}$. In addition, WAT PPAR $\gamma$ downregulation was observed in adult rats programmed by maternal obesity ${ }^{(46)}$. We speculate that decreased PPAR $\gamma$ in VIS WAT of HF female offspring is associated with decreased adipogenesis, and therefore this could lead to hypertrophy of preexisting adipocytes in consequence of fat overload imposed by maternal HF diet. Surprisingly, we observed decreased ACC content in VIS WAT of female HF offspring. As ACC is a lipogenic enzyme and HF females presented increased VIS WAT adipocyte diameter, we speculated that this profile might be related to decreased PPAR $\gamma$ in this group, as the simultaneous down-regulation of PPAR $\gamma$ and $\mathrm{ACC}^{(77-79)}$ has been shown in adipocytes.
To better understand the sex-specific effect of maternal HF diet on the ECS in VIS WAT, we evaluated the content of $\mathrm{ER} \alpha$ and $\mathrm{ER} \beta$ in adipose tissue of male and female offspring. Maternal HF diet reduced $\mathrm{ER} \alpha$ and $\mathrm{ER} \beta$ content only in VIS WAT of female pups in parallel to increased CB1. In a very recent paper, it was demonstrated that oestradiol increases cannabinoid receptor expression in the uterus of ovariectomised rats ${ }^{(33)}$, but the direct role of oestrogen on adipose tissue CB1 content is unknown, and, possibly, oestrogen regulates $\mathrm{CB} 1$ in a tissue-specific manner.

It has been proposed that $\mathrm{ER} \alpha$ mediates beneficial metabolic effects of oestrogens, such as anti-lipogenesis, improvement of insulin sensitivity, reduction of body weight, decrease of adipose tissue mass ${ }^{(80)}$ and prevention of white adipocyte hypertrophy ${ }^{(81)}$. Therefore, the reduced VIS WAT ER $\alpha$ content corroborates the increased VIS adiposity, VIS adipocyte hypertrophy and hyperinsulinaemia presented in HF female offspring. ER $\alpha$ is the predominant ER in WAT, whereas the role of $\mathrm{ER} \beta$ is poorly known in this tissue ${ }^{(82)}$. It was previously demonstrated that ER $\beta$ knockout mice presented increased body weight gain and fat mass when fed a HF $\operatorname{diet}^{(83)}$, and ER $\beta$ agonist reduced VIS fat mass and adipocyte size in ovariectomised rats ${ }^{(84)}$. Therefore, the decreased ER $\beta$ content in VIS WAT of HF female offspring also corroborates the increased body weight, VIS adiposity and VIS adipocyte hypertrophy in female HF offspring. 
(a)

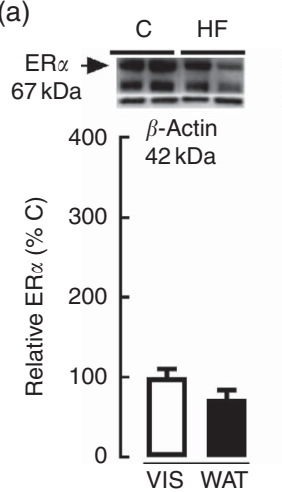

(b)

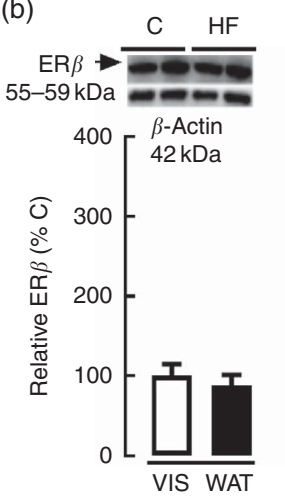

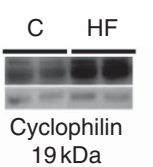
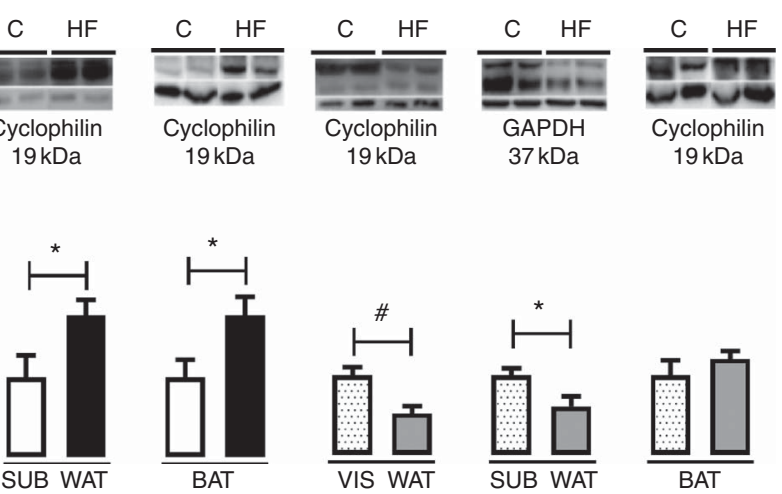
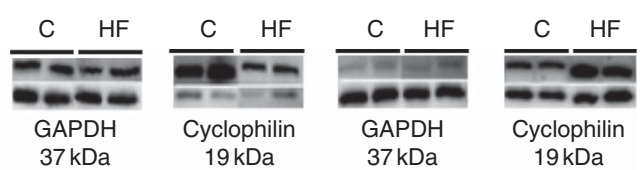

Fig. 6. Effect of maternal high-fat (HF) diet on oestrogen receptor (ER) content in white and brown adipose tissue of rat offspring at weaning. (a) Protein content of ERa in visceral white adipose tissue (VIS WAT), subcutaneous WAT (SUB WAT) and brown adipose tissue (BAT) of control (C) and HF male and female offspring, and (b) protein content of $\mathrm{ER} \beta$ of $\mathrm{C}$ and $\mathrm{HF}$ male and female offspring. Values are means ( $n 6$ or 7 pups from different litters/group), with their standard errors represented by vertical bars. $\square, \mathrm{C}$ male; $\square$, HF male; $\square, \mathrm{C}$ female; $\square$, HF female; GAPDH, glyceraldehyde-3-phosphate dehydrogenase. Statistically significant differences were determined by Student's unpaired $t$ test between control and HF offspring per each gender. ${ }^{*} P<0.05, \# P<0.01, \$ P<0.0001$.

Table 4. General effect of maternal high-fat (HF) diet on the protein content of the endocannabinoid system components, adipocyte function markers and thermogenic markers in visceral white adipose tissue (WAT), subcutaneous WAT and brown adipose tissue (BAT) of the offspring

\begin{tabular}{|c|c|c|c|c|c|c|}
\hline \multirow[b]{2}{*}{ Parameters } & \multicolumn{2}{|c|}{ VIS WAT } & \multicolumn{2}{|c|}{ SUB WAT } & \multicolumn{2}{|c|}{ BAT } \\
\hline & $\begin{array}{l}\mathrm{HF} \\
\text { male }\end{array}$ & $\begin{array}{c}\mathrm{HF} \\
\text { female }\end{array}$ & $\begin{array}{c}\mathrm{HF} \\
\text { male }\end{array}$ & $\begin{array}{c}\mathrm{HF} \\
\text { female }\end{array}$ & $\begin{array}{l}\mathrm{HF} \\
\text { male }\end{array}$ & $\begin{array}{c}\mathrm{HF} \\
\text { female }\end{array}$ \\
\hline CB1 & $=$ & $\uparrow$ & $\downarrow$ & $\downarrow$ & $\uparrow$ & $\uparrow$ \\
\hline CB2 & $=$ & $=$ & $\downarrow$ & $=$ & $=$ & $\downarrow$ \\
\hline $\mathrm{FAAH}$ & $\uparrow$ & $=$ & $\uparrow$ & $\uparrow$ & $=$ & $\uparrow$ \\
\hline MAGL & $=$ & $=$ & $=$ & $\uparrow$ & $\uparrow$ & $\uparrow$ \\
\hline Perilipin & $=$ & $=$ & $=$ & $\uparrow$ & un & un \\
\hline PPARY & $=$ & $\downarrow$ & $=$ & $=$ & un & un \\
\hline CEPB $a$ & $\downarrow$ & $=$ & $=$ & $=$ & un & un \\
\hline ACC & $\uparrow$ & $\downarrow$ & $=$ & $\uparrow$ & un & un \\
\hline FAS & $=$ & $=$ & $=$ & $=$ & un & un \\
\hline UCP1 & $=$ & $=$ & $\downarrow$ & $=$ & $=$ & $\uparrow$ \\
\hline TH & $\downarrow$ & $=$ & $=$ & $\downarrow$ & $=$ & $\uparrow$ \\
\hline$A R \beta 3$ & un & un & un & un & $=$ & $=$ \\
\hline $\mathrm{ER} a$ & $=$ & $\downarrow$ & $\uparrow$ & $\downarrow$ & $\uparrow$ & $=$ \\
\hline $\mathrm{ER} \beta$ & $=$ & $\downarrow$ & $=$ & $=$ & $=$ & $\uparrow$ \\
\hline
\end{tabular}

CB1, cannabinoid type-1 receptor; $=$, unchanged; $\uparrow$, increased; $\downarrow$, decreased; CB2 cannabinoid type-2 receptor; FAAH, fatty acid amide hydrolase; MAGL, monoacylglycerol lipase; un, unmeasured; CEBPa, CCAAT/enhancer binding protein $a$ ACC, acetyl-CoA carboxylase; FAS, fatty acid synthase; UCP1, uncoupling protein 1; AR $\beta 3$, adrenergic receptor $\beta 3$; $\mathrm{TH}$, tyrosine hydroxylase; ER $a$, oestrogen receptor $a, \mathrm{ER} \beta$, oestrogen receptor $\beta$.
In SUB WAT, in contrast to VIS WAT, maternal HF diet decreased CB1 content and increased FAAH content in both male and female offspring. This profile indicates reduced CB1 signalling and decreased AEA levels ${ }^{(62,63)}$. Furthermore, in female pups, maternal HF diet also increased MAGL content, which indicates reduced 2 -AG levels ${ }^{(85,86)}$. Here, we demonstrated that the reduced CB1 content in SUB WAT was sex independent and may occur because of metabolic features of this depot. CB1 knockout SUB adipocytes showed increased lipid accumulation during adipogenesis and decreased apoptosis compared with wild-type SUB adipocyte ${ }^{(87)}$.

In SUB WAT of male offspring, maternal HF diet also decreased CB2 content. The role of CB2 is still unclear in energy metabolism regulation ${ }^{(88)}$. Generally, CB2 expression has been associated with inflammatory processes, but in vivo and in vitro studies show controversial results with regard to proinflammatory $v$. anti-inflammatory profile ${ }^{(89-92)}$. It was already shown that the CB2 agonist treatment reduced white adipose mass and white adipocyte cell size in mice ${ }^{(89)}$. Thus, the decreased CB2 content might be associated with increased SUB adiposity and adipocyte hypertrophy in SUB WAT of HF male offspring. In addition, maternal HF diet increased ER $\alpha$ in SUB WAT of HF male offspring. However, these molecular changes in SUB WAT of male offspring were not associated with changes in lipogenic or adipogenic markers. It is possible that the 
ECS and oestrogen signalling changes in this fat depot may be associated with lipolysis markers not evaluated in the present study. In contrast, in SUB WAT of female offspring, maternal HF diet decreased ER $\alpha$ content, which may be associated with lipogenic stimulus and corroborates the higher content of perilipin and ACC with adipocyte hypertrophy observed in this group.

The present findings with regard to the effect of maternal HF diet on the ECS and ER in different white adipose compartments of the offspring clearly show a dimorphic effect of this maternal nutritional insult. However, it is still unclear why a similar phenotype in VIS WAT of female HF offspring and SUB WAT of HF male offspring was observed, with quite different molecular signatures. Although VIS WAT of HF female offspring presented a 'deleterious' molecular profile, SUB WAT of male HF offspring presented a 'beneficial profile' characterised by decreased $\mathrm{CB} 1$ and $\mathrm{CB} 2$ and increased FAAH and ER $\alpha$. This discordant association between the ECS, ER and lipogenesis/hypertrophy in HF offspring may arise from several reasons. First, CB1 differentially regulates VIS and SUB WAT. In mice, decreased CB1 in VIS depot is associated with decreased differentiation, whereas it is associated with increased differentiation in SUB depot $^{(87)}$. In this distinct regulation, CB1 may favour fat redistribution from SUB to VIS compartments, as previously suggested by Di Marzo ${ }^{(93)}$. Moreover, VIS WAT and SUB WAT present distinct gene expression modulation by Rimonabant (CB1 antagonist) in obese mice ${ }^{(69)}$, suggesting the differential role of $\mathrm{CB} 1$ in each adipose depot. Here, we observed decreased CB1 in SUB WAT of male and female HF offspring, but only HF females presented higher CB1 VIS WAT content, showing that the dimorphism of CB1 is more related to VAT. A similar profile was observed in overweight humans, with decreased content of CB1 in SUB WAT and increased CB1 content in VIS WAT ${ }^{(94)}$. Second, the absolute content of CB1 is likely different between VIS and SUB, which can differently impact the energy metabolism ${ }^{(51,52,94)}$. However, there is still no consensus with regard to the relative CB1 expression between these two WAT depots. Third, the association between obesity and CB1 content in WAT is also contradictory. It was demonstrated that CB1 expression is decreased in SUB WAT of obese patients, ${ }^{(52)}$ and its expression in rescued after weight lost ${ }^{(95)}$. Contrarily, Engeli et al. ${ }^{(96)}$ did not find any difference in CB1 content between lean and obese patients.

To further investigate the mechanisms that could be involved in the differential regulation of the ECS in WAT of HF offspring, we assessed the levels of 'browning' in VIS WAT and SUB WAT by measuring UCP1 and TH tissue content. It has been proposed that increased adrenergic signalling in SUB WAT stimulates UCP1 expression, a marker of 'browning', in parallel to increased CB1 and decreased CB2 expression ${ }^{(97)}$. In agreement, here we observed decreased content of UCP1 in SUB WAT of male HF offspring in parallel to decreased CB1 in these depots, but also increased levels of CB2. Increased UCP1 in SUB WAT of male offspring corroborates a recent study by Zou et $a l .{ }^{(98)}$. In addition, it was demonstrated that decreased levels of endocannabinoids in SUB WAT decreases local thermogenic markers ${ }^{(99)}$. In contrast, in SUB WAT of female HF offspring, we observed decreased levels of $\mathrm{TH}$, suggesting decreased adrenergic signalling, which was also associated with decreased CB1 content without changes in CB2. Interestingly, an important distinction between male and female SUB WAT is the content of $\mathrm{ER} \alpha$, which was increased in male and decreased in female HF offspring. These data suggest that maternal HF diet modulates cannabinoid receptors in SUB WAT of the offspring at least in part by integrative changes in adrenergic signalling, 'browning' levels and oestrogen signalling.

The thermogenic function of BAT is completely dependent on SNS and can be inhibited by the $\operatorname{ECS}^{(100)}$. Maternal HF diet increased BAT weight and lipid content in male and female offspring, corroborating data from maternal HF diet and litter reduction experimental models ${ }^{(101,102)}$. In BAT, maternal HF diet increased CB1 and MAGL content in the offspring, independently of sex, whereas it increased FAAH content only in female offspring. The increased content of degrading enzymes suggests reduced local levels of AEA and 2-AG, as previously shown in genetic and diet obese models ${ }^{(50)}$, and might be an adaptive consequence of up-regulation of CB1 in BAT. To investigate whether the ECS changes induced by maternal HF diet in BAT occurred in parallel with changes in thermogenic markers, we evaluated BAT content of UCP1, and the catecholamine signalling markers $\mathrm{TH}$ and $\mathrm{AR} \beta 3$. Maternal HF diet did not alter thermogenic markers in BAT of male pups but increased TH and UCP1 content in female pups. The relationship between the ECS and thermogenesis has been characterised using in vivo and in vitro experimental models. In vivo, CB1 antagonism results in increased BAT UCP1 content, increased BAT temperature and energy expenditure, with reduced weight gain in intact and BAT-denervated rats ${ }^{(103,104)}$. Similar results were observed in vitro using differentiated brown adipocytes ${ }^{(105)}$. In contrast, pharmacological or cold activation of the sympathetic signalling in BAT of mice results in increased CB1 mRNA levels and decreased CB2 mRNA levels in parallel to increased $\mathrm{UCP} 1^{(97)}$. Therefore, using in vivo models, it is difficult to establish causality between the ECS changes and BAT markers. Moreover, in the present study, we used weanling rats, which are still under the effect of maternal HF diet through breast milk, and hyperenergetic food intake can activate diet-dependent thermogenesis ${ }^{(106)}$. We speculate that maternal HF-activated diet induced thermogenesis stimulating sympathetic activation of BAT by increasing TH content, which increased UCP1 and differentially regulated CB1 and CB2 in female pups, similar to cold-induced effects on the $\operatorname{ECS}^{(97)}$.

Besides catecholamine signalling, the UCP1 expression and thermogenesis are stimulated by oestrogen and $\mathrm{T} 3^{(107,108)}$. Female HF offspring presented increased plasma levels of T3, suggesting higher T3 signalling in BAT, without changes in oestrogen serum levels. However, maternal HF diet increased $\mathrm{ER} \beta$ content in female offspring, whereas it increased ER $\alpha$ content in male offspring, suggesting higher sensitivity to oestrogen in BAT.

There are several mechanisms known to be associated with DOHaD that could contribute to the sex-dependent and depotdependent programming of adipose tissue in the present study. In a general view, programming is associated with epigenetic regulation of transcription by changing the levels of DNA methylation, histone acetylation/methylation and ncRNA. 
Offspring epigenome can be influenced by age, sex, and nutritional factors among other modulators ${ }^{(109)}$. For example, obese rat offspring from obese dams present altered fatty acid composition within WAT, with decreased content of PUFA ${ }^{(110)}$, key regulators of the ECS's components and adipogenic markers such as PPAR $\gamma$. More specifically, some of the ECS's components are regulated by epigenetic mechanisms ${ }^{(111)}$, which deserves deeper investigation in future experiments of programming by maternal nutritional insults.

In addition, each adipose tissue depot presents its unique signature of developmental gene expression showing differential profile even within the same general type, that is, VIS or SUB depots. This gene expression signature includes different levels of PPAR and CEBP, which are highly influenced by the hormonal milieu. Leptin differentially regulates PPAR $\gamma 2$ in WAT, as leptin-deficient obese mice present higher PPAR $\gamma 2$ content in the SUB WAT and decreased PPAR $\gamma 2$ in VIS WAT, compared with control mice ${ }^{(112)}$. Altered leptin level in early life is likely a key imprinting factor of energy homoeostasis and obesity in several programming models, including maternal HF diet ${ }^{(113)}$. One of the marked features of the present model is that HF offspring present hyperleptinaemia across life, which could differentially modulate the ECS's components in VIS WAT and SUB WAT.

As regards the sex-specific programming of the ECS, we speculated that it may be related to oestrogen regulation, as the presence of response elements to oestrogen in Cnr1 and Faah promoter region ${ }^{(30,32)}$ has been reported. Androgen and progesterone may also be involved in the ECS's programming. Androgen response element was also described in the Cnr1 promoter region ${ }^{(34)}$. However, very little is known as regards the direct ECS regulation by sex steroids, even in control rats/ mice/humans. Another important fact that requires attention is the age of the offspring in the present study. We used weanling rats, that is, before puberty and the rise of circulating levels of sex hormones, as we observed unchanged oestradiol serum levels. We speculate that the ECS's modulation is taking place, at least in part, through the regulation of oestrogen sensitivity and ER differential content among the several adipose compartments analysed in our experiment. Finally, the modulation of ECS linked to chromosomal sex (XX $v$. XY) should be considered as a sexual dimorphism mechanism ${ }^{(114)}$

The main limitations of the present study include the lack of measurement of tissue content of the endocannabinoids AEA and 2-AG to provide a clearer interpretation of the results concerning the content of the metabolising enzymes FAAH and MAGL. Moreover, although we showed the sex difference in the expression pattern of ER in the different adipose depots, the biological mechanisms mediating sex bias have not been clearly defined. Further investigation into the direct effect of oestrogens and androgens on the ECS's components is necessary in future studies.

In conclusion, maternal HF diet during the perinatal period induced early obesity in the offspring, independently of the sex, but induced differential regulation of the adipose tissue's ECS's components between male and female offspring at weaning. Sex-specific ECS changes seem to be more evident in white adipose depots compared with brown adipose depots. The ECS changes occurred in parallel to alteration of molecular markers of adipogenesis, lipogenesis and thermogenesis as well as differential ER content across the adipose tissue depots. Collectively, our results suggest that the ECS is highly regulated in early life in response to nutritional milieu and may be involved in the early origins of metabolic disorders.

\section{Acknowledgements}

The authors are grateful for the technical support provided by Luela Dias and Juliana Penna.

This study was supported by the Carlos Chagas Filho Research Foundation of the State of Rio de Janeiro (FAPERJ) (grant no. E-26/202.816/2015) and National Council for Scientific and Technological Development (CNPq) (grant no. 473807/2013-0).

M. M. A., C. P. D.-R., A. S. S. and M. F. M. have participated in animal experiments, collection and interpretation of data. L. S. M. contributed with the morphological analysis. I. H. T. and C. C. P.-M delineated experimental design and supervised the study. M. M. A., C. P. D.-R., C. C. P.-M. and I. H. T. have written the manuscript.

None of the authors has any conflicts of interest to declare.

\section{References}

1. Burgio E, Lopomo A \& Migliore L (2015) Obesity and diabetes: from genetics to epigenetics. Mol Biol Rep 42, 799-818.

2. Stang J \& Huffman LG (2016) Position of the Academy of Nutrition and Dietetics: obesity, reproduction, and pregnancy outcomes. J Acad Nutr Diet 116, 677-691.

3. Langley-Evans SC (2015) Nutrition in early life and the programming of adult disease: a review. J Hum Nutr Diet $\mathbf{2 8}$, Suppl. 1, 1-14.

4. Ma X, Lee P, Chisholm DJ, et al. (2015) Control of adipocyte differentiation in different fat depots; implications for pathophysiology or therapy. Front Endocrinol (Lausanne) 6, 1 .

5. Ibrahim MM (2010) Subcutaneous and visceral adipose tissue: structural and functional differences. Obes Rev 11, 11-18.

6. Pellegrinelli V, Carobbio S \& Vidal-Puig A (2016) Adipose tissue plasticity: how fat depots respond differently to pathophysiological cues. Diabetologia 59, 1075-1088.

7. Labbe SM, Caron A, Lanfray D, et al. (2015) Hypothalamic control of brown adipose tissue thermogenesis. Front Syst Neurosci 9, 150.

8. Kooijman S, van den Heuvel JK \& Rensen PC (2015) Neuronal control of brown fat activity. Trends Endocrinol Metab 26, 657-668.

9. Saito M, Yoneshiro T \& Matsushita M (2016) Activation and recruitment of brown adipose tissue by cold exposure and food ingredients in humans. Best Pract Res Clin Endocrinol Metab 30, 537-547.

10. Hepler C, Vishvanath L \& Gupta RK (2017) Sorting out adipocyte precursors and their role in physiology and disease. Genes Dev 31, 127-140.

11. Wankhade UD, Shen M, Yadav H, et al. (2016) Novel browning agents, mechanisms, and therapeutic potentials of brown adipose tissue. Biomed Res Int 2016, 2365609. 
12. Rocha-Rodrigues S, Rodriguez A, Gouveia AM, et al. (2016) Effects of physical exercise on myokines expression and brown adipose-like phenotype modulation in rats fed a high-fat diet. Life Sci 165, 100-108.

13. Cohen P \& Spiegelman BM (2015) Brown and beige fat: molecular parts of a thermogenic machine. Diabetes $\mathbf{6 4}$ 2346-2351.

14. Cristino L, Becker T \& Di Marzo V (2014) Endocannabinoids and energy homeostasis: an update. Biofactors 40, 389-397.

15. D'Addario C, Micioni Di Bonaventura MV, Pucci M, et al. (2014) Endocannabinoid signaling and food addiction. Neurosci Biobehav Rev 47, 203-224.

16. Matias I \& Di Marzo V (2007) Endocannabinoids and the control of energy balance. Trends Endocrinol Metab 18, $27-37$.

17. Maccarrone M, Bab I, Biro T, et al. (2015) Endocannabinoid signaling at the periphery: 50 years after THC. Trends Pharmacol Sci 36, 277-296.

18. Krentz AJ, Fujioka K \& Hompesch M (2016) Evolution of pharmacological obesity treatments: focus on adverse side-effect profiles. Diabetes Obes Metab 18, 558-570.

19. Keimpema E, Calvigioni D \& Harkany T (2013) Endocannabinoid signals in the developmental programming of delayed-onset neuropsychiatric and metabolic illnesses. Biochem Soc Trans 41, 1569-1576.

20. D'Asti E, Long H, Tremblay-Mercier J, et al. (2010) Maternal dietary fat determines metabolic profile and the magnitude of endocannabinoid inhibition of the stress response in neonatal rat offspring. Endocrinology 151, 1685-1694.

21. Ramirez-Lopez MT, Arco R, Decara J, et al. (2016) Exposure to a highly caloric palatable diet during the perinatal period affects the expression of the endogenous cannabinoid system in the brain, liver and adipose tissue of adult rat offspring. PLOS ONE 11, e0165432.

22. Ramirez-Lopez MT, Arco R, Decara J, et al. (2016) Long-term effects of prenatal exposure to undernutrition on cannabinoid receptor-related behaviors: sex and tissue-specific alterations in the mRNA expression of cannabinoid receptors and lipid metabolic regulators. Front Behav Neurosci 10, 241.

23. Ramirez-Lopez MT, Vazquez M, Bindila L, et al. (2015) Exposure to a highly caloric palatable diet during pregestational and gestational periods affects hypothalamic and hippocampal endocannabinoid levels at birth and induces adiposity and anxiety-like behaviors in male rat offspring. Front Behav Neurosci 9, 339.

24. Franco JG, Fernandes TP, Rocha CP, et al. (2012) Maternal high-fat diet induces obesity and adrenal and thyroid dysfunction in male rat offspring at weaning. J Physiol 590, 5503-5518.

25. Freitas HR, Isaac AR, Malcher-Lopes R, et al. (2017) Polyunsaturated fatty acids and endocannabinoids in health and disease. Nutr Neurosci 7, 1-20.

26. Kim J, Carlson ME, Kuchel GA, et al. (2016) Dietary DHA reduces downstream endocannabinoid and inflammatory gene expression and epididymal fat mass while improving aspects of glucose use in muscle in $\mathrm{C} 57 \mathrm{BL} / 6 \mathrm{~J}$ mice. Int $J$ Obes (Lond) 40, 129-137.

27. Buettner C, Muse ED, Cheng A, et al. (2008) Leptin controls adipose tissue lipogenesis via central, STAT3-independent mechanisms. Nat Med 14, 667-675.

28. Cristino L, Busetto G, Imperatore R, et al. (2013) Obesitydriven synaptic remodeling affects endocannabinoid control of orexinergic neurons. Proc Natl Acad Sci US A 110, E2229-E2238.
29. Cristino L, Luongo L, Imperatore R, et al. (2016) Orexin-A and endocannabinoid activation of the descending antinociceptive pathway underlies altered pain perception in leptin signaling deficiency. Neuropsychopharmacology $\mathbf{4 1}$, 508-520.

30. Proto MC, Gazzerro P, Di Croce L, et al. (2012) Interaction of endocannabinoid system and steroid hormones in the control of colon cancer cell growth. J Cell Physiol 227, 250-258.

31. Lee KS, Asgar J, Zhang Y, et al. (2013) The role of androgen receptor in transcriptional modulation of cannabinoid receptor type 1 gene in rat trigeminal ganglia. Neuroscience 254, 395-403.

32. Waleh NS, Cravatt BF, Apte-Deshpande A, et al. (2002) Transcriptional regulation of the mouse fatty acid amide hydrolase gene. Gene 291, 203-210.

33. Maia J, Almada M, Silva A, et al. (2017) The endocannabinoid system expression in the female reproductive tract is modulated by estrogen. I Steroid Biochem Mol Biol (epublication ahead of print version 22 July 2017).

34. Grimaldi P, Pucci M, Di Siena S, et al. (2012) The faah gene is the first direct target of estrogen in the testis: role of histone demethylase LSD1. Cell Mol Life Sci 69, 4177-4190.

35. Drummond GB (2009) Reporting ethical matters in the Journal of Physiology: standards and advice. J Physiol 587, 713-719.

36. Marques RG, Morales MM \& Petroianu A (2009) Brazilian law for scientific use of animals. Acta Cir Bras 24, 69-74.

37. Reeves PG, Nielsen FH \& Fahey GC Jr (1993) AIN-93 purified diets for laboratory rodents: final report of the American Institute of Nutrition ad hoc writing committee on the reformulation of the AIN-76A rodent diet. J Nutr 123, 1939-1951.

38. Fischbeck KL \& Rasmussen KM (1987) Effect of repeated reproductive cycles on maternal nutritional status, lactational performance and litter growth in ad libitum-fed and chronically food-restricted rats. J Nutr 117, 1967-1975.

39. Faul F, Erdfelder E, Lang AG, et al. (2007) G*Power 3: a flexible statistical power analysis program for the social, behavioral, and biomedical sciences. Behav Res Methods 39, 175-191.

40. Oliveira LS, Souza LL, Souza AF, et al. (2016) Perinatal maternal high-fat diet promotes alterations in hepatic lipid metabolism and resistance to the hypolipidemic effect of fish oil in adolescent rat offspring. Mol Nutr Food Res 60, 2493-2504.

41. Lopez-Jaramillo P, Gomez-Arbelaez D, Lopez-Lopez J, et al. (2014) The role of leptin/adiponectin ratio in metabolic syndrome and diabetes. Horm Mol Biol Clin Investig 18, $37-45$.

42. Ahima RS (2011) Digging deeper into obesity. J Clin Invest 121, 2076-2079.

43. Nakano Y, Itabashi K, Sakurai M, et al. (2014) Accumulation of subcutaneous fat, but not visceral fat, is a predictor of adiponectin levels in preterm infants at term-equivalent age. Early Hum Dev 90, 213-217.

44. Hansen-Pupp I, Hellgren G, Hard AL, et al. (2015) Early surge in circulatory adiponectin is associated with improved growth at near term in very preterm infants. J Clin Endocrinol Metab 100, 2380-2387.

45. Friedman JM \& Halaas JL (1998) Leptin and the regulation of body weight in mammals. Nature 395, 763-770.

46. Lecoutre S, Deracinois B, Laborie C, et al. (2016) Depot- and sex-specific effects of maternal obesity in offspring's adipose tissue. $J$ Endocrinol 230, 39-53. 
47. Desai M, Jellyman JK, Han G, et al. (2014) Maternal obesity and high-fat diet program offspring metabolic syndrome. Am J Obstet Gynecol 211, 237.e1-237.e13.

48. Franco JG, Dias-Rocha CP, Fernandes TP, et al. (2016) Resveratrol treatment rescues hyperleptinemia and improves hypothalamic leptin signaling programmed by maternal high-fat diet in rats. Eur J Nutr 55, 601-610.

49. Bjorbaek C (2009) Central leptin receptor action and resistance in obesity. J Investig Med 57, 789-794.

50. Iannotti FA, Piscitelli F, Martella A, et al. (2013) Analysis of the 'endocannabinoidome' in peripheral tissues of obese Zucker rats. Prostaglandins Leukot Essent Fatty Acids 89, $127-135$.

51. Bennetzen MF, Nielsen TS, Paulsen SK, et al. (2010) Reduced cannabinoid receptor 1 protein in subcutaneous adipose tissue of obese. Eur J Clin Invest 40, 121-126.

52. Bluher M, Engeli S, Kloting N, et al. (2006) Dysregulation of the peripheral and adipose tissue endocannabinoid system in human abdominal obesity. Diabetes $\mathbf{5 5}$ 3053-3060.

53. Bordicchia M, Battistoni I, Mancinelli L, et al. (2010) Cannabinoid CB1 receptor expression in relation to visceral adipose depots, endocannabinoid levels, microvascular damage, and the presence of the Cnr1 A3813G variant in humans. Metabolism 59, 734-741.

54. Cardinal P, Bellocchio L, Clark S, et al. (2012) Hypothalamic CB1 cannabinoid receptors regulate energy balance in mice. Endocrinology 153, 4136-4143.

55. Jelsing J, Larsen PJ \& Vrang N (2009) The effect of leptin receptor deficiency and fasting on cannabinoid receptor 1 mRNA expression in the rat hypothalamus, brainstem and nodose ganglion. Neurosci Lett 463, 125-129.

56. Armitage JA, Poston L \& Taylor PD (2008) Developmental origins of obesity and the metabolic syndrome: the role of maternal obesity. Front Horm Res 36, 73-84.

57. Fonseca BM, Correia-da-Silva G, Taylor AH, et al. (2012) Characterisation of the endocannabinoid system in rat haemochorial placenta. Reprod Toxicol 34, 347-356.

58. Wu J, Gouveia-Figueira S, Domellof M, et al. (2016) Oxylipins, endocannabinoids, and related compounds in human milk: Levels and effects of storage conditions. Prostaglandins Other Lipid Mediat 122, 28-36.

59. Vaswani K, Chan HW, Peiris HN, et al. (2015) Gestation related gene expression of the endocannabinoid pathway in rat placenta. Mediators Inflamm 2015, 850471.

60. Aguirre CA, Castillo VA \& Llanos MN (2012) Excess of the endocannabinoid anandamide during lactation induces overweight, fat accumulation and insulin resistance in adult mice. Diabetol Metab Syndr 4, 35.

61. Aguirre CA, Castillo VA \& Llanos MN (2015) The endocannabinoid anandamide during lactation increases body fat content and CB1 receptor levels in mice adipose tissue. Nutr Diabetes 5, e167.

62. Henry RJ, Kerr DM, Flannery LE, et al. (2017) Pharmacological inhibition of FAAH modulates TLR-induced neuroinflammation, but not sickness behaviour: an effect partially mediated by central TRPV1. Brain Behav Immun 62, 318-331.

63. Engeli S, Bohnke J, Feldpausch M, et al. (2005) Activation of the peripheral endocannabinoid system in human obesity. Diabetes 54, 2838-2843.

64. Murdolo G, Kempf K, Hammarstedt A, et al. (2007) Insulin differentially modulates the peripheral endocannabinoid system in human subcutaneous abdominal adipose tissue from lean and obese individuals. J Endocrinol Invest 30, RC17-RC21.
65. Cable JC, Tan GD, Alexander SP, et al. (2011) The activity of the endocannabinoid metabolising enzyme fatty acid amide hydrolase in subcutaneous adipocytes correlates with BMI in metabolically healthy humans. Lipids Health Dis 10, 129.

66. Silvestri C \& Di Marzo V (2013) The endocannabinoid system in energy homeostasis and the etiopathology of metabolic disorders. Cell Metab 17, 475-490.

67. Tang QQ, Gronborg M, Huang H, et al. (2005) Sequential phosphorylation of CCAAT enhancer-binding protein beta by MAPK and glycogen synthase kinase 3beta is required for adipogenesis. Proc Natl Acad Sci U S A 102, 9766-9771.

68. Gaggini M, Saponaro C \& Gastaldelli A (2015) Not all fats are created equal: adipose vs. ectopic fat, implication in cardiometabolic diseases. Horm Mol Biol Clin Investig 22, $7-18$.

69. Jourdan T, Djaouti L, Demizieux L, et al. (2010) CB1 antagonism exerts specific molecular effects on visceral and subcutaneous fat and reverses liver steatosis in diet-induced obese mice. Diabetes 59, 926-934

70. Shanik MH, Xu Y, Skrha J, et al. (2008) Insulin resistance and hyperinsulinemia: is hyperinsulinemia the cart or the horse? Diabetes Care 31, S262-S268.

71. Juan CC, Chen KH, Wang PH, et al. (2015) Endocannabinoid system activation may be associated with insulin resistance in women with polycystic ovary syndrome. Fertil Steril 104, 200-206.

72. Pagano C, Pilon C, Calcagno A, et al. (2007) The endogenous cannabinoid system stimulates glucose uptake in human fat cells via phosphatidylinositol 3-kinase and calciumdependent mechanisms. J Clin Endocrinol Metab 92, 4810-4819.

73. Okuno A, Tamemoto H, Tobe K, et al. (1998) Troglitazone increases the number of small adipocytes without the change of white adipose tissue mass in obese Zucker rats. J Clin Invest 101, 1354-1361.

74. Zhang J, Fu M, Cui T, et al. (2004) Selective disruption of PPARgamma 2 impairs the development of adipose tissue and insulin sensitivity. Proc Natl Acad Sci US A 101, 10703-10708.

75. Medina-Gomez G, Virtue S, Lelliott C, et al. (2005) The link between nutritional status and insulin sensitivity is dependent on the adipocyte-specific peroxisome proliferator-activated receptor-gamma2 isoform. Diabetes 54, 1706-1716.

76. Johnson JA, Trasino SE, Ferrante AW Jr, et al. (2007) Prolonged decrease of adipocyte size after rosiglitazone treatment in high- and low-fat-fed rats. Obesity (Silver Spring) 15, 2653-2663.

77. Li KK, Liu CL, Shiu HT, et al. (2016) Cocoa tea (Camellia ptilophylla) water extract inhibits adipocyte differentiation in mouse 3T3-L1 preadipocytes. Sci Rep 6, 20172.

78. Song Y, Kim MB, Kim C, et al. (2016) 5,7-dimethoxyflavone attenuates obesity by inhibiting adipogenesis in 3T3-L1 adipocytes and high-Fat diet-induced obese C57BL/6J mice. J Med Food 19, 1111-1119.

79. Sharma BR, Oh J, Kim HA, et al. (2015) Anti-obesity effects of the mixture of eriobotrya japonica and nelumbo nucifera in adipocytes and high-fat diet-induced obese mice. Am J Chin Med 43, 681-694.

80. Bluher M (2013) Importance of estrogen receptors in adipose tissue function. Mol Metab 2, 130-132.

81. Heine PA, Taylor JA, Iwamoto GA, et al. (2000) Increased adipose tissue in male and female estrogen receptor-alpha knockout mice. Proc Natl Acad Sci U S A 97, 12729-12734.

82. Barros RP, Gabbi C, Morani A, et al. (2009) Participation of ERalpha and ERbeta in glucose homeostasis in skeletal 
muscle and white adipose tissue. Am J Physiol Endocrinol Metab 297, E124-E133.

83. Foryst-Ludwig A, Clemenz M, Hohmann S, et al. (2008) Metabolic actions of estrogen receptor beta (ERbeta) are mediated by a negative cross-talk with PPARgamma. PLOS Genet 4, e1000108.

84. Weigt C, Hertrampf T, Zoth N, et al. (2012) Impact of estradiol, ER subtype specific agonists and genistein on energy homeostasis in a rat model of nutrition induced obesity. Mol Cell Endocrinol 351, 227-238.

85. Pasquarelli N, Porazik C, Hanselmann J, et al. (2015) Comparative biochemical characterization of the monoacylglycerol lipase inhibitor KML29 in brain, spinal cord, liver, spleen, fat and muscle tissue. Neuropharmacology $\mathbf{9 1}$, 148-156

86. Vander Tuig JG, Kerner J \& Romsos DR (1985) Hypothalamic obesity, brown adipose tissue, and sympathoadrenal activity in rats. Am J Physiol 248, E607-E617.

87. Wagner IV, Perwitz N, Drenckhan M, et al. (2011) Cannabinoid type 1 receptor mediates depot-specific effects on differentiation, inflammation and oxidative metabolism in inguinal and epididymal white adipocytes. Nutr Diabetes 1, e16

88. Soethoudt M, Grether U, Fingerle J, et al. (2017) Cannabinoid CB2 receptor ligand profiling reveals biased signalling and off-target activity. Nat Commun 8, 13958.

89. Verty AN, Stefanidis A, McAinch AJ, et al. (2015) Anti-obesity effect of the CB2 receptor agonist JWH-015 in diet-induced obese mice. PLOS ONE 10, e0140592.

90. Chiurchiu V, Lanuti M, Catanzaro G, et al. (2014) Detailed characterization of the endocannabinoid system in human macrophages and foam cells, and anti-inflammatory role of type-2 cannabinoid receptor. Atherosclerosis 233, 55-63.

91. Ueda Y, Miyagawa N \& Wakitani K (2007) Involvement of cannabinoid $\mathrm{CB} 2$ receptors in the IgE-mediated triphasic cutaneous reaction in mice. Life Sci 80, 414-419.

92. Deveaux V, Cadoudal T, Ichigotani Y, et al. (2009) Cannabinoid CB2 receptor potentiates obesity-associated inflammation, insulin resistance and hepatic steatosis. PLOS ONE $\mathbf{4}$, e5844.

93. Di Marzo V (2008) The endocannabinoid system in obesity and type 2 diabetes. Diabetologia 51, 1356-1367.

94. Sarzani R, Bordicchia M, Marcucci P, et al. (2009) Altered pattern of cannabinoid type 1 receptor expression in adipose tissue of dysmetabolic and overweight patients. Metabolism 58, 361-367.

95. Bennetzen MF, Wellner N, Ahmed SS, et al. (2011) Investigations of the human endocannabinoid system in two subcutaneous adipose tissue depots in lean subjects and in obese subjects before and after weight loss. Int $J$ Obes (Lond) 35, 1377-1384.

96. Engeli S, Lehmann AC, Kaminski J, et al. (2014) Influence of dietary fat intake on the endocannabinoid system in lean and obese subjects. Obesity (Silver Spring) 22, E70-E76.
97. Krott LM, Piscitelli F, Heine M, et al. (2016) Endocannabinoid regulation in white and brown adipose tissue following thermogenic activation. J Lipid Res 57, 464-473.

98. Zou T, Chen D, Yang Q, et al. (2017) Resveratrol supplementation of high-fat diet-fed pregnant mice promotes brown and beige adipocyte development and prevents obesity in male offspring. J Physiol 595, 1547-1562.

99. Geurts L, Everard A, Van Hul M, et al. (2015) Adipose tissue NAPE-PLD controls fat mass development by altering the browning process and gut microbiota. Nat Commun 6, 6495.

100. Quarta C, Bellocchio L, Mancini G, et al. (2010) CB(1) signaling in forebrain and sympathetic neurons is a key determinant of endocannabinoid actions on energy balance. Cell Metab 11, 273-285.

101. de Almeida DL, Fabricio GS, Trombini AB, et al. (2013) Early overfeed-induced obesity leads to brown adipose tissue hypoactivity in rats. Cell Physiol Biochem 32, 1621-1630.

102. Liang X, Yang Q, Zhang L, et al. (2016) Maternal high-fat diet during lactation impairs thermogenic function of brown adipose tissue in offspring mice. Sci Rep 6, 34345.

103. Verty AN, Allen AM \& Oldfield BJ (2009) The effects of rimonabant on brown adipose tissue in rat: implications for energy expenditure. Obesity (Silver Spring) 17, 254-261.

104. Hsiao WC, Shia KS, Wang YT, et al. (2015) A novel peripheral cannabinoid receptor 1 antagonist, BPR0912, reduces weight independently of food intake and modulates thermogenesis. Diabetes Obes Metab 17, 495-504.

105. Boon MR, Kooijman S, van Dam AD, et al. (2014) Peripheral cannabinoid 1 receptor blockade activates brown adipose tissue and diminishes dyslipidemia and obesity. FASEB J 28, 5361-5375.

106. Lettieri Barbato D, Tatulli G, Vegliante R, et al. (2015) Dietary fat overload reprograms brown fat mitochondria. Front Physiol 6, 272.

107. Townsend KL \& Tseng YH (2014) Brown fat fuel utilization and thermogenesis. Trends Endocrinol Metab 25, 168-177.

108. Lopez M \& Tena-Sempere M (2016) Estradiol and brown fat. Best Pract Res Clin Endocrinol Metab 30, 527-536.

109. Lillycrop KA \& Burdge GC (2015) Maternal diet as a modifier of offspring epigenetics. J Dev Orig Health Dis 6, 88-95.

110. Benkalfat NB, Merzouk H, Bouanane S, et al. (2011) Altered adipose tissue metabolism in offspring of dietary obese rat dams. Clin Sci (Lond) 121, 19-28.

111. D'Addario C, Di Francesco A, Pucci M, et al. (2013) Epigenetic mechanisms and endocannabinoid signalling. FEBS $J$ 280, 1905-1917.

112. Yamamoto Y, Gesta S, Lee KY, et al. (2010) Adipose depots possess unique developmental gene signatures. Obesity (Silver Spring) 18, 872-878.

113. Breton C (2013) The hypothalamus-adipose axis is a key target of developmental programming by maternal nutritional manipulation. J Endocrinol 216, R19-R31.

114. Valencak TG, Osterrieder A \& Schulz TJ (2017) Sex matters: the effects of biological sex on adipose tissue biology and energy metabolism. Redox Biol 12, 806-813. 